\title{
Obsolescencia lingüística, descripción gramatical y documentación de lenguas en el Perú: hacia un estado de la cuestión
}

\author{
Roberto Zariquiey \\ Pontificia Universidad Católica del Perú \\ Harald Hammarström \\ Uppsala University \\ Mónica Arakaki \\ Arturo Oncevay \\ John Miller \\ Aracelli García \\ Adriano Ingunza \\ Pontificia Universidad Católica del Perú
}

\section{Resumen}

Siguiendo los métodos propuestos y las herramientas desarrolladas por Hammarström, Castermans, Forkel et al. (2018) para la visualización simultánea de índices de vitalidad lingüística y descripción gramatical, el presente artículo ofrece un análisis cuantitativo y cualitativo de los logros alcanzados y los desafíos pendientes en materia de documentación y descripción de la diversidad lingüística peruana. Se busca contribuir a determinar las verdaderas dimensiones de nuestro conocimiento sobre la diversidad lingüística de nuestro país y proponer algunas prioridades para una futura política para la diversidad lingüística peruana en la que 
descripción, documentación y revitalización se entiendan como tareas indesligables.

Palabras clave: lenguas peruanas, documentación lingüística, descripción gramatical, obsolescencia lingüística

\section{Abstract}

Following the methods and tools developed by Hammarström, Castermans, Forkel et al. (2018) for the simultaneous visualization of the vitality status and degree of documentation of the world's languages, this paper provides a quantitative and qualitative analysis of the achievements and the challenges in the documentation and description of Peruvian languages. We attempt to determine the real dimensions of our understanding of the linguistic diversity of our country, and we propose some priorities the description, documentation and revitalization of Peruvian languages.

Keywords: Peruvian languages, language documentation, grammatical description, linguistic obsolescence

\section{Introducción}

El Año Internacional de las Lenguas Indígenas es el marco ideal para reflexionar críticamente sobre la situación de la diversidad lingüística mundial y las amenazas que esta enfrenta. En este contexto, el grado de conocimiento y documentación de las más de 7000 lenguas habladas en la actualidad es una pregunta crucial. De acuerdo con Noonan (2006), solo existen gramáticas comprehensivas de alrededor de 500 lenguas y contamos con bosquejos gramaticales y diccionarios para otras 2000. Para otras 2500, solo existen estudios concentrados en algún aspecto gramatical específico, mientras que para las 2000 restantes contamos solamente con datos léxicos muy pobres o con ninguna información. A partir de estos datos, Noonan concluye que "not only are most of the world's languages inadequately described, but given the rate at which languages are becoming moribund or extinct, we are engaged in a race against time [and against war, poverty, and the good and bad effects of globalization] to preserve as much of the world's linguistic heritage as possible" (2006: 114). 
El presente artículo ofrece un análisis cualitativo y cuantitativo de los logros alcanzados y los desafíos pendientes en materia de documentación y descripción de la diversidad lingüística peruana. Se busca contribuir a determinar las verdaderas dimensiones de nuestro conocimiento sobre la diversidad lingüística de nuestro país y trazar algunas prioridades para el futuro. Siguiendo los métodos propuestos y las herramientas desarrolladas por Hammarström, Castermans, Forkel et al. (2018) para la visualización simultánea de índices de vitalidad lingüística y descripción gramatical, este estudio describe por primera vez la interacción entre estas variables para las lenguas peruanas.

Este estudio identifica aquellas lenguas peruanas en peligro que no cuentan con una descripción y/o una documentación adecuadas y ofrece un balance general de las gramáticas disponibles para las lenguas peruanas. Muchas de las lenguas que cuentan con descripciones gramaticales no han sido estudiadas siguiendo un marco teórico afín a los paradigmas tipológicos que dan forma a la gramaticografía contemporánea. En realidad, muchas de estas gramáticas han sido elaboradas en el marco de modelos que pueden considerarse obsoletos (como la tagmémica) o se basan en datos puramente elicitados que no trascienden el nivel de la oración. Una de las conclusiones de este estudio es, entonces, que todavía se requieren descripciones más completas y actuales de muchas de nuestras lenguas, aunque se cuente con estudios previos sobre varias de ellas. La situación es más preocupante cuando nos movemos al terreno de la documentación: el porcentaje de lenguas peruanas para las que contamos con bases de datos en algún archivo del mundo no supera el 50 \% y el impacto de estas bases de datos en la vida lingüística de los pueblos es todavía incipiente, ya que no existen nexos sólidos entre documentación y revitalización de lenguas peruanas. Esperamos que este estudio contribuya a generar políticas para que el Estado, la academia y las comunidades de habla trabajen de forma colaborativa en la descripción, documentación y revitalización de nuestras lenguas. 
El presente estudio está organizado como sigue: en $\$ 2$ reflexionamos sobre el número de lenguas peruanas; en $\$ 3$ discutimos las interacciones entre grado de descripción y estatus de vitalidad de las lenguas peruanas; en $\mathbb{4}$ exploramos la tradición gramaticográfica sobre lenguas peruanas y en $\$ 5$ ofrecemos un panorama de los avances en documentación de lenguas peruanas. Finalmente, en $\$ 6$ damos algunas conclusiones y recomendaciones.

\section{Sobre el número de lenguas habladas en nuestro país}

Aunque en el Documento Nacional de Lenguas Originarias del Perú el Estado peruano lista 47 lenguas indígenas (Ministerio de Educación del Perú 2013), en la actualidad, se habla oficialmente de 48 lenguas indígenas peruanas. Se cuentan cuatro lenguas andinas y 44 lenguas amazónicas. La diferencia entre ambas cifras se relaciona con la reconsideración del ashéninka como una lengua indígena independiente del asháninka (ver discusión más abajo). La lista de lenguas indígenas peruanas reconocidas por el Estado se ofrece en la Tabla 1. Las lenguas aparecen organizadas de acuerdo a su filiación genética y se distingue entre familias lingüísticas andinas y amazónicas (la información ha sido adaptada de Ministerio de Educación del Perú 2013, con la inclusión del ashéninka).

Para completar el panorama de la diversidad lingüística peruana es necesario incluir a la lengua de señas peruanas (LSP), que en los últimos años viene siendo objeto de estudio por parte de un equipo liderado por el lingüista peruano Miguel Rodríguez Mondoñedo. Si incluimos a dicha lengua, en el Perú, siguiendo las cifras oficiales, tenemos 49 lenguas, además del castellano. La cifra contrasta radicalmente con la ofrecida por Glottolog (Hammarström, Forkel y Haspelmath 2018), en donde se cuentan 116 lenguas peruanas, 26 ya extintas y 90 para las que todavía contamos con hablantes. La cifra del Estado peruano no incluye lenguas extintas, por lo que el dato que requiere explicación es la diferencia entre 49 y 90 lenguas (la cifra oficial —incluyendo a la lengua de señas peruana-y la cifra de lenguas vivas peruanas 
según Glottolog, respectivamente). La lista completa de lenguas peruanas identificadas en Glottolog se presenta más adelante en la Tabla 10, donde además se da información sobre el estatus de vitalidad y el grado de descripción de cada una.

Tabla 1. Lenguas indígenas reconocidas por el Estado peruano por familia lingüística

\begin{tabular}{|c|c|c|}
\hline $\begin{array}{l}\text { Familia } \\
\text { lingüística }\end{array}$ & Lenguas & Región \\
\hline aru & aimara, cauqui, jaqaru & andina \\
\hline quechua & quechua & andina \\
\hline jíbaro & achuar, awajún, wampis & amazónica \\
\hline pano & $\begin{array}{l}\text { amahuaca, capanahua, cashinahua, isconahua, } \\
\text { kakataibo, matsés, shipibo-konibo, sharanahua, } \\
\text { yaminahua, yora (nahua) }\end{array}$ & amazónica \\
\hline záparo & arabela, iquitu, taushiro & amazónica \\
\hline arawak & $\begin{array}{l}\text { asháninka, ashéninka, chamicuro, iñapari, } \\
\text { kakinte (caquinte), matsigenka, nanti, } \\
\text { nomatsigenga, resígaro, yanesha, yine }\end{array}$ & amazónica \\
\hline bora & bora & amazónica \\
\hline takana & ese eja & amazónica \\
\hline harakbut & harakbut & amazónica \\
\hline kandozi & kandozi-chapra & amazónica \\
\hline tupí-guaraní & kukama-kukamiria, omagua & amazónica \\
\hline arawa & madija (culina) & amazónica \\
\hline tukano & maijuna, secoya & amazónica \\
\hline muniche & muniche & amazónica \\
\hline witoto & murui-muinani, ocaina & amazónica \\
\hline kawapana & shawi, shiwilu & amazónica \\
\hline tikuna & tikuna (ticuna) & amazónica \\
\hline urarina & urarina & amazónica \\
\hline
\end{tabular}


Una rápida comparación entre ambas tablas revela que las claras diferencias entre ambos estimados provienen principalmente del hecho de que Glottolog identifica 30 "lenguas" quechua, mientras que las cifras oficiales del Estado peruano consideran al quechua como una sola lengua. El problema del estatus de las variedades quechuas ( $\mathrm{y}$ si estas son lenguas o dialectos) tiene larga data en la lingüística andina. Sin embargo, lo que sí constituye un acuerdo generalizado es que el término "quechua" responde en realidad a una unidad genética internamente compleja que puede catalogarse de familia lingüística. Las tres propuestas de clasificación interna de la familia quechua (Cerrón-Palomino 1987; Parker 1963; Torero 1964) no proponen una distinción clara entre lenguas y dialectos, $y$, por lo general, hablan de ramas, subgrupos y dialectos. El quechua Huaihuash de Cerrón-Palomino (1987) es equivalente, en términos generales, al quechua I de Torero (1964) y al quechua B de Parker (1963). El quechua Huámpuy de Cerrón-Palomino (1987) es, por su parte, equivalente al quechua II de Torero y al quechua A de Parker.

La pregunta sigue siendo, sin embargo, si los nueve dialectos de la rama Huaihuash (Q1; QB), es decir, Pacaraos, Huailas, Conchucos, Alto Pativilca, Alto Marañón, Alto Huallaga, Yaru, Jauja-Huanca y Huangáscar-Topará, son lenguas o dialectos. La misma pregunta aplica para las 15 variedades de quechua Huámpuy: Laraos, Lincha, Apurí, Chocos, Madeán, Cañaris-Incahuasi, Cajamarca, Amazonas, San Martín, Loreto, Ecuador, Colombia, Ayacucho, Cuzco-Bolivia, Argentina. Y para ambas ramas queda abierta la pregunta sobre si los "dialectos" identificados son en realidad conjuntos de variedades, como ocurre con el quechua ecuatoriano (Montaluisa 2018). Es obvio que una respuesta definitiva a esta pregunta debería considerar no solo criterios lingüísticos, sino también sociales, culturales, políticos e históricos, que van más allá del objetivo de este artículo. El número de 30 lenguas quechuas consignado por Glottolog no responde a un estudio comparativo de las variedades lingüísticas que componen esta familia, sino a la sistematización de las fuentes bibliográficas disponibles. Este número por lo demás está en constante revisión. 
Otro punto de discrepancia entre ambas propuestas tiene que ver con las variedades lingüísticas del ashéninka-asháninka: solo se reconocen dos lenguas en los documentos oficiales del Estado peruano, pero hay un total de siete lenguas de esta rama identificadas en Glottolog. Esta propuesta se corresponde con el análisis de Pedrós (2018), que constituye la discusión más reciente al respecto. Pedrós (2018) propone una clasificación de las variedades del conglomerado ashéninka-asháninka como una cadena dialectal. Propone una separación de dicha cadena en tres grupos principales: el asháninka o grupo sur, el ashéninka del noroeste (conformado por las variedades del Alto Perené, el Pichis y el Apurucayali y el Yurúa) y el ashéninka del noreste (conformado por las variedades del Pajonal y el Ucayali). Pedrós establece sus clasificaciones a partir de criterios lingüísticos, basados en una rigurosa aplicación del método comparativo. La propuesta de Glottolog a este respecto es tratar las siete variedades identificadas por Pedrós como lenguas.

Otras diferencias entre ambas listas las encontramos en el tratamiento del huachipaeri, amarakaeri y arazaire como lenguas - por lo general, son consideradas dialectos de harakmbut (Lyon 1975)y del tratamiento del mashco piro — variedad lingüística de un grupo indígena en aislamiento voluntario- como lengua independiente y no como dialecto del yine.

Mención aparte merecen la identificación de tres lenguas de señas en el Perú por Glottolog, que sigue la propuesta de Clark (2017). Este es un tema polémico y los especialistas peruanos sostienen que los argumentos de Clark requieren de una revisión (Alexandra Arnaiz, comunicación personal). Una diferencia extra entre ambas propuestas se relaciona con el tratamiento del castellano amazónico como entidad lingüística independiente (con glottocode propio) en Glottolog. Independientemente de sus diferencias, las variedades de castellano habladas en el Perú son todas consideradas dialectos del castellano tanto para el Estado como para la academia peruana.

Es importante mencionar finalmente que solo en un caso el Estado peruano reconoce una lengua que no es considerada como tal en Glottolog: se trata del cauqui, que no es distinguida del jaqaru 
en Glottolog, ${ }_{1}^{1}$ pero es considerada una de las cuatro lenguas andinas peruanas de acuerdo a la propuesta oficial del Estado peruano. Ciertamente, el cauqui, lengua muy amenazada ( 9 hablantes, según Crevels 2012: 209), amerita estudios más profundos.

No queremos ahondar en los problemas inherentes a "contar" lenguas. En realidad, la diferencia entre lengua y dialecto es, en buena cuenta, subjetiva y diversos factores sociales y políticos tienen un rol determinante en tal distinción. Sin embargo, es claro que para los fines del presente estudio la propuesta (potencialmente hiperdiferenciadora) de Glottolog es la que resulta más útil. En realidad, lo que interesa es conocer el estado de vitalidad y el grado de documentación de las variedades lingüísticas habladas en el Perú, independientemente de si se las considera dialectos o lenguas. Preguntar por el grado de descripción o el estatus de vitalidad del "quechua” como entidad lingüística sin subdistinciones, simplemente, carece de sentido, dada la enorme diversidad de situaciones sociolingüísticas que encierra. Y lo mismo ocurre en los otros casos discutidos aquí. La desaparición de un dialecto o de una lengua (o de un género discursivo, para tal fin) nos parece siempre preocupante.

3. Visualización simultánea de vitalidad lingüística y descripción de lenguas en el Perú

\subsection{Las fuentes}

En esta sección, presentamos los resultados de nuestras exploraciones computacionales a los datos ofrecidos por Glottolog, el cual es un sitio web que ofrece información sobre la diversidad lingüística mundial. Incluye un inventario comprehensivo de lenguas, dialectos y familias lingüísticas. Además, ofrece una propuesta de

La edición siguiente de Glottolog va a incluir cauqui como lengua independiente basándose en el testimonio de Hardman (1978: 148) que aclara que los hablantes del jaqaru y cauqui no pueden entender o ayudar a transcribir grabaciones de la otra variedad. 
clasificación de las lenguas en familias, información sobre la ubicación geográfica de cada lengua y listados bibliográficos detallados.

Si bien Glottolog no cuenta con información sobre estatus de vitalidad, esta información puede ser obtenida de otras fuentes, tales como el Atlas de las lenguas en peligro del mundo (Unesco s/f), Ethnologue (s/f) y el Catálogo de las lenguas en peligro de la Universidad de Hawái en Manoa (s/f). Cada una de estas fuentes usa sus propios criterios para determinar el estado de vitalidad de una lengua y propone distintas categorías solo parcialmente equivalentes. ${ }^{2}$

En lo que toca al Atlas de las lenguas en peligro del mundo, el método empleado es el de la Unesco, Language Vitality and Endangerment framework (Brenzinger et al. 2003), que establece seis categorías para el índice de vitalidad lingüística, resumidas en la Tabla 2. Tal como se puede apreciar en dicha tabla, el criterio central para la determinación de la vitalidad de una lengua es la transmisión intergeneracional.

Tabla 2. Categorías de vitalidad por Unesco

\begin{tabular}{ll}
\hline Categoría & Descripción \\
\hline $\begin{array}{l}\text { segura } \\
\text { vulnerable }\end{array}$ & $\begin{array}{l}\text { la lengua es hablada por todas las generaciones } \\
\text { los niños hablan la lengua pero solo en ciertos dominios } \\
\text { definitivamente } \\
\text { en peligro }\end{array}$ \\
$\begin{array}{l}\text { severamente } \\
\text { en peligro }\end{array}$ & $\begin{array}{l}\text { los niños ya no aprenden la lengua como su lengua materna } \\
\text { extinta }\end{array}$ \\
\hline
\end{tabular}

Por su parte, Ethnologue usa el llamado Expanded Graded Intergenerational Disruption Scale (EGIDS) (Lewis y Simons 2010) para determinar el estado de vitalidad de una lengua. EGIDS propone hasta 13 diferentes categorías de lenguas de acuerdo a su vitalidad y constituye un modelo bastante más complejo que el empleado por Unesco. Una versión resumida se presenta en la Tabla 3.

2 Para una discusión detallada, ver Hammarström, Castermans, Forkel et al. (2018). 
Tabla 3. Categorías de vitalidad por EGIDS

\begin{tabular}{|c|c|}
\hline Categoría & Descripción \\
\hline 0 internacional & la lengua se usa internacionalmente \\
\hline 1 nacional & la lengua es usada en diversos dominios en el país \\
\hline 2 regional & la lengua se usa públicamente en la región donde se habla \\
\hline 3 comercial & la lengua se usa para el comercio nacional o internacional \\
\hline 4 educativa & la lengua cuenta con un sistema educativo público \\
\hline 5 escrita & la lengua se usa oralmente y algunos hablantes la escriben \\
\hline 6 a vigorosa & la lengua se habla en la comunidad y es aprendida por los niños \\
\hline $6 \mathrm{~b}$ amenazada & $\begin{array}{l}\text { la lengua se habla en la comunidad pero es aprendida solo por } \\
\text { algunos niños }\end{array}$ \\
\hline 7 en reemplazo & la lengua ya no se transmite a los niños \\
\hline 8 a moribunda & la lengua solo es hablada por abuelos \\
\hline 8 b casi extinta & la lengua solo la conocen los abuelos, pero ya no la usan \\
\hline 9 dormida & $\begin{array}{l}\text { la lengua ya no se habla fluidamente y sirve solo como } \\
\text { vehículo de identidad }\end{array}$ \\
\hline 10 extinta & $\begin{array}{l}\text { ya nadie habla la lengua ni mantiene un vínculo de identidad } \\
\text { con ella }\end{array}$ \\
\hline
\end{tabular}

Finalmente, el catálogo de las lenguas en peligro de la Universidad de Hawái (ELCat) usa el Language Endangerment Index (Campbell 2017: 4-5; Lee y Van Way 2018). ELCat establece cuatro variables para determinar el grado de peligro de una lengua: transmisión intergeneracional, número absoluto de hablantes, tendencias en el número de hablantes y dominios de uso. A partir de estas cuatro variables, ELCat identifica 6 grados para medir el estado de vitalidad de las lenguas, tal como se detalla en la tabla 4.

La idea de combinar los datos de Glottolog y de las fuentes disponibles para conocer el estado de vitalidad de las lenguas del mundo se ha plasmado en las herramientas computacionales GlottoScope (http://glottolog.org/langdoc/status) y GlottoVis (http://glammap. win.tue.nl/glottovis), de reciente implementación (Hammarström, Forkel y Haspelmath 2018). GlottoScope y GlottoVis hacen uso 
Tabla 4. Categorías de vitalidad de acuerdo a ELCat

\begin{tabular}{|c|c|c|c|c|}
\hline Categoría & Transmisión & \# hablantes & $\begin{array}{l}\text { Tendencias en el \# } \\
\text { de hablantes }\end{array}$ & $\begin{array}{l}\text { Dominios de } \\
\text { uso }\end{array}$ \\
\hline 0 a salvo & $\begin{array}{l}\text { toda la } \\
\text { comunidad } \\
\text { habla la } \\
\text { lengua }\end{array}$ & $>100000$ & $\begin{array}{l}\text { número de } \\
\text { miembros del } \\
\text { grupo étnico es } \\
\text { igual al número } \\
\text { de hablantes y el } \\
\text { número es estable } \\
\text { o va en aumento }\end{array}$ & $\begin{array}{l}\text { se usa en } \\
\text { todos los } \\
\text { dominios }\end{array}$ \\
\hline 1 vulnerable & $\begin{array}{l}\text { adultos y } \\
\text { algunos niños } \\
\text { hablan la } \\
\text { lengua }\end{array}$ & $10000-99999$ & $\begin{array}{l}\text { número de } \\
\text { miembros del } \\
\text { grupo étnico es } \\
\text { casi equivalente } \\
\text { al número de } \\
\text { hablantes y el } \\
\text { número está } \\
\text { decreciendo }\end{array}$ & $\begin{array}{l}\text { no se usa } \\
\text { en espacios } \\
\text { oficiales }\end{array}$ \\
\hline 2 amenazada & $\begin{array}{l}\text { solo los } \\
\text { adultos } \\
\text { hablan la } \\
\text { lengua }\end{array}$ & $1000-9999$ & $\begin{array}{l}\text { la mayoría de } \\
\text { miembros del } \\
\text { grupo étnico habla } \\
\text { la lengua (pero } \\
\text { el número está } \\
\text { decreciendo) }\end{array}$ & $\begin{array}{l}\text { se usa en } \\
\text { espacios no } \\
\text { oficiales, } \\
\text { principal- } \\
\text { mente el } \\
\text { hogar }\end{array}$ \\
\hline 3 en peligro & $\begin{array}{l}\text { solo hablan } \\
\text { la lengua } \\
\text { algunos } \\
\text { adultos }\end{array}$ & $100-999$ & $\begin{array}{l}\text { la mitad de la } \\
\text { comunidad habla } \\
\text { la lengua (pero } \\
\text { el número está } \\
\text { decreciendo) }\end{array}$ & $\begin{array}{l}\text { solo en el } \\
\text { hogar }\end{array}$ \\
\hline $\begin{array}{l}4 \text { severamente } \\
\text { en peligro }\end{array}$ & $\begin{array}{l}\text { la lengua solo } \\
\text { es hablada } \\
\text { por los } \\
\text { abuelos }\end{array}$ & $10-99$ & $\begin{array}{l}\text { menos de la mitad } \\
\text { de la comunidad } \\
\text { habla la lengua }\end{array}$ & $\begin{array}{l}\text { se usa solo } \\
\text { en el hogar } \\
\text { donde ya no } \\
\text { es la lengua } \\
\text { dominante }\end{array}$ \\
\hline $\begin{array}{l}5 \text { críticamente } \\
\text { en peligro }\end{array}$ & $\begin{array}{l}\text { solo hay } \\
\text { unos pocos } \\
\text { hablantes }\end{array}$ & $1-9$ & $\begin{array}{l}\text { solo un porcentaje } \\
\text { pequeño de la } \\
\text { comunidad habla la } \\
\text { lengua y el número } \\
\text { de hablantes } \\
\text { está decreciendo } \\
\text { rápidamente }\end{array}$ & $\begin{array}{l}\text { solo se usa } \\
\text { en dominios } \\
\text { específicos y } \\
\text { limitados }\end{array}$ \\
\hline
\end{tabular}


de un modelo matemático que agrupa y establece correspondencias entre los tres modelos de medición de la vitalidad de una lengua presentados en esta sección. Este modelo lleva por nombre Agglomerated Endangerment Scale (AES). El AES establece seis categorías, cuya correspondencia con los modelos previos es presentada en la Tabla 5.

Tabla 5. Mapeo de las categorías de obsolescencia en AES

\begin{tabular}{llll}
\hline Unesco & ELCat & EGIDS & AES \\
\hline a salvo & a salvo & $\begin{array}{l}\text { nacional } \\
\text { regional } \\
\text { comercial } \\
\text { educativa } \\
\text { escrita } \\
\text { vigorosa }\end{array}$ & no en peligro \\
vulnerable & vulnerable & amenazada & amenazada \\
$\begin{array}{l}\text { definitivamente en } \\
\text { peligro }\end{array}$ & amenazada en peligro & en reemplazo & en reemplazo \\
severamente en peligro & $\begin{array}{l}\text { severamente en } \\
\text { peligro }\end{array}$ & moribunda & moribunda \\
críticamente en peligro & $\begin{array}{l}\text { críticamente en } \\
\text { peligro }\end{array}$ & casi extinta & casi extinta \\
& $\begin{array}{l}\text { durmiente } \\
\text { despertando }\end{array}$ & $\begin{array}{l}\text { durmiente } \\
\text { despertando } \\
\text { solo segunda } \\
\text { lengua }\end{array}$ & extinta \\
& & extinta & \\
& & &
\end{tabular}

Nota. Adaptada de Hammarström, Forkel y Haspelmath (2018: 373)

\subsection{Resultados}

Este artículo se basa en la metodología de AES, por lo que las lenguas peruanas serán catalogas en su escala de vitalidad de seis grados de obsolescencia: no en peligro, amenazada, cambiante, moribunda, casi extinta y extinta. El contenido de cada una de estas categorías se establece a partir de sus relaciones e interac- 
ciones con las metodologías presentadas propuestas por Unesco, EGIDS y ELCat. Si bien la distinción entre las categorías amenazada y en reemplazo (término que se emplea para aquellos casos en los que encontramos un cambio drástico hacia una lengua nacional) no es siempre clara a partir de los datos disponibles, las otras categorías son lo suficientemente transparentes como para ser utilizadas de forma segura en el contexto peruano.

Los datos de AES para las 116 lenguas peruanas identificadas por Glottolog se resumen en la Tabla 6 y en la Figura 1. De las 105 lenguas identificadas por Glottolog, solo 9 pueden catalogarse como no en peligro, mientras que 25 ya están extintas. El resto se ubica en los distintos grados de vitalidad ofrecidos por AES (y amenazada es la categoría más recurrente).

Por otro lado, nuestras exploraciones computacionales de los datos bibliográficos de Glottolog revelan los resultados presentados en la Tabla 7 y en la Figura 2. El estado de descripción de una lengua se mide a partir de una escala que indica el grado máximo alcanzado en la descripción de una lengua. Los grados identificados son los siguientes: gramática (la lengua tiene una descripción gramatical comprehensiva), bosquejo gramatical (la lengua cuenta con una descripción gramatical menor estructurada en forma de bosquejo y, por lo general, menor a las 80 páginas), diccionario (la lengua cuenta con un diccionario o vocabulario), rasgo específico (existen solo estudios de algún rasgo gramatical específico para la lengua), fonología (hay una descripción fonológica de la lengua), texto (la lengua cuenta con textos publicados), lista léxica (la lengua cuenta con una lista léxica menor, tipo Swadesh) y estudio comparativo (hay datos de la lengua en algún estudio comparativo, por ejemplo, de reconstrucción). La idea es catalogar el nivel máximo alcanzado para cada lengua. Si una lengua recibe la calificación gramática, puede contar también con cualquiera de los objetos asociados a las categorías inferiores. Si una lengua es catalogada como lista de palabras, ese es el grado máximo de documentación disponible para la lengua y no hay nada más elaborado que eso. 
Tabla 6. Situación de las lenguas peruanas 1: vitalidad

\begin{tabular}{ccl}
\hline \#lenguas & $\%$ & Grado de vitalidad \\
\hline 9 & 7.75 & no en peligro \\
31 & $\mathbf{2 6 . 7 2}$ & amenazada \\
24 & 20.68 & en reemplazo \\
10 & $\mathbf{8 . 6 2}$ & moribunda \\
16 & 13.79 & casi extinta \\
26 & 22.41 & extinta \\
\hline
\end{tabular}

Figura 1. Situación de las lenguas peruanas 1: vitalidad

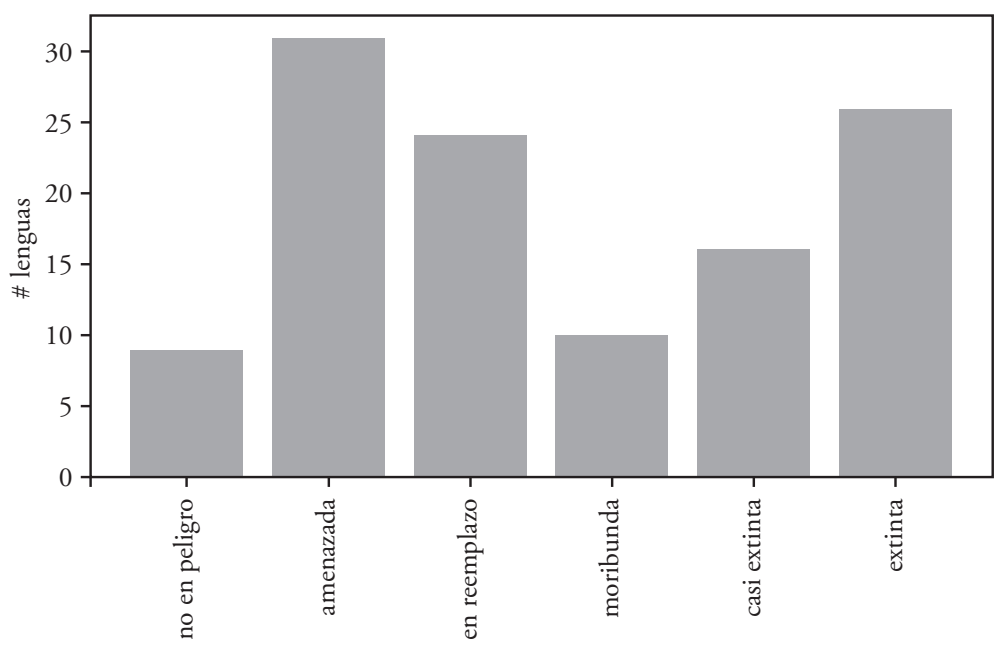


Tabla 7. Situación de las lenguas peruanas 2: estado de la descripción

\begin{tabular}{ccl}
\hline \#lenguas & $\%$ & Estado de descripción \\
\hline 49 & 54.44 & gramática \\
28 & 31.11 & bosquejo gramatical \\
2 & 2.22 & diccionario \\
3 & 3.33 & rasgo específico \\
2 & 2.22 & fonología \\
2 & 2.22 & texto \\
1 & 1.11 & lista léxica \\
3 & 3.33 & comparativo \\
\hline
\end{tabular}

Figura 2. Situación de las lenguas peruanas 2: estado de la descripción

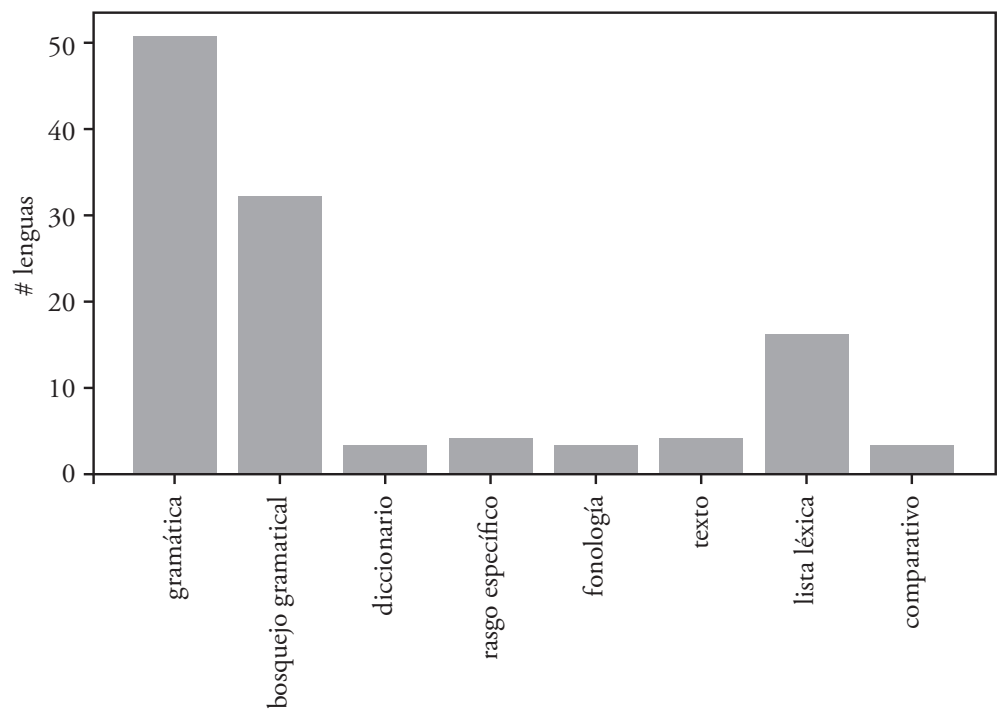


Tabla 8. Publicaciones sobre lenguas peruanas en Glottolog

\begin{tabular}{lc}
\hline Clase & \# de hits \\
\hline lista léxica & 94 \\
dialectología & 5 \\
bibliografía & 7 \\
gramática & 103 \\
sociolingüística & 13 \\
diccionario & 91 \\
etnografía & 105 \\
texto & 21 \\
rasgo específico & 72 \\
fonología & 44 \\
bosquejo gramatical & 141 \\
caracterización general & 125 \\
estudio comparativo & 82 \\
nuevo testamento & 4 \\
estudio mínimo & 32 \\
\hline
\end{tabular}

Tal como se puede apreciar, de las 90 lenguas peruanas no extintas en Glottolog, 49 alcanzan el grado de documentación máximo (gramática) y otras 28 alcanzan el grado de bosquejo gramatical. Eso significa que contamos con descripciones gramaticales para 77 lenguas peruanas, de las 90 reconocidas por Glottolog. Esta cifra resulta alta a primera vista, pero en $\$ 4$ ofrecemos una caracterización general de las fuentes y reevaluamos esta cifra en el contexto de establecer prioridades para el trabajo a futuro con lenguas indígenas peruanas. Lo que resulta claro también a partir de la Tabla es que 13 lenguas peruanas no cuentan con ningún bosquejo gramatical o gramática comprehensiva. El estudio gramatical de las 13 lenguas en esa lista ( $y$, particularmente, de las que se encuentren en peligro) constituye una prioridad. 
La búsqueda de todas las publicaciones listadas en Glottolog para lenguas peruanas da un total de 939 hits clasificados en las categorías listadas en la Tabla 7 y otras que se añaden para facilitar la presentación de los resultados de la Tabla 8. El dato, sin embargo, debe ser tomado con cautela, ya que Glottolog no es necesariamente exhaustivo. En realidad, es probable que las publicaciones mayores sobre lenguas peruanas sí se vean representadas, pero no así las referencias de acceso más restringido o difícil.

Tal como lo anunciamos desde la introducción, el objetivo central de este estudio es ofrecer una extrapolación de los datos relacionados a estatus de vitalidad y grado de descripción de las lenguas peruanas, con la finalidad de identificar aquellos casos de lenguas en peligro para las que existe poco trabajo descriptivo. Los datos gruesos de este experimento se presentan en la Tabla 9. La tabla está estructurada de la siguiente forma: en la primera columna, encontramos los estatus de vitalidad y, en la segunda, los grados de descripción. En la tercera columna, ofrecemos el número de lenguas que cumplen con las características estipuladas en las columnas 1 y 2. Finalmente, el porcentaje correspondiente a ese número se ofrece en la cuarta columna.

Tabla 9. Lenguas peruanas: extrapolación, descripción y vitalidad

\begin{tabular}{llcc}
\hline Vitalidad & Descripción & \# lenguas & $\%$ \\
\hline no en peligro & gramática & 2 & 1.72 \\
no en peligro & bosquejo gramatical & 6 & 5.17 \\
no en peligro & texto & 1 & 0.86 \\
amenazada & gramática & 18 & 15.51 \\
amenazada & bosquejo gramatical & 8 & $\mathbf{6 . 8 9}$ \\
amenazada & rasgo específico & 2 & 1.72 \\
amenazada & texto & 1 & $\mathbf{0 . 8 6}$ \\
amenazada & lista léxica & 1 & $\mathbf{0 . 8 6}$ \\
amenazada & comparativo & 1 & $\mathbf{0 . 8 6}$ \\
\hline
\end{tabular}




\begin{tabular}{llcc}
\hline Vitalidad & Descripción & \# lenguas & $\%$ \\
\hline en reemplazo & gramática & 18 & 15.51 \\
en reemplazo & bosquejo gramatical & 4 & 3.44 \\
en reemplazo & diccionario & 1 & 0.86 \\
en reemplazo & fonología & 1 & 0.86 \\
moribunda & gramática & 3 & 2.58 \\
moribunda & bosquejo gramatical & 3 & 2.58 \\
moribunda & diccionario & 1 & 0.86 \\
moribunda & rasgo específico & 1 & 0.86 \\
moribunda & comparativo & 2 & 1.72 \\
casi extinta & gramática & 7 & $\mathbf{6 . 0 3}$ \\
casi extinta & bosquejo gramatical & 7 & $\mathbf{6 . 0 3}$ \\
casi extinta & diccionario & 1 & 0.86 \\
casi extinta & fonología & 1 & 0.86 \\
extinta & gramática & 3 & 2.58 \\
extinta & bosquejo gramatical & 4 & 3.44 \\
extinta & rasgo específico & 1 & 0.86 \\
extinta & fonología & 1 & 0.86 \\
extinta & texto & 2 & 1.72 \\
extinta & lista léxica & 15 & 12.93 \\
\hline & & &
\end{tabular}

La lista completa de lenguas peruanas en Glottolog con información sobre su estatus de vitalidad y su grado de descripción se presenta en la Tabla 10. La información presentada allí es crucial para trazar cualquier plan centrado en el estudio de las lenguas peruanas con prioridades claras y bien establecidas. 
Tabla 10. Situación de las lenguas peruanas (lista de Glottolog)

\begin{tabular}{|c|c|c|c|c|}
\hline Prioridad & Lengua & ISO 639-3 & Amenaza & Descripción \\
\hline 1 & sensi & sni & extinta & lista léxica \\
\hline 2 & remo del río Moa & rem & extinta & lista léxica \\
\hline 3 & omurano & omu & extinta & lista léxica \\
\hline 4 & hibito & hib & extinta & lista léxica \\
\hline 5 & cahuarano & $\mathrm{cah}$ & extinta & lista léxica \\
\hline 6 & aushiri & avs & extinta & lista léxica \\
\hline 7 & atsahuaca & atc & extinta & lista léxica \\
\hline 8 & tallán & - & extinta & lista léxica \\
\hline 9 & sechura & - & extinta & lista léxica \\
\hline 10 & remo del río Blanco & - & extinta & lista léxica \\
\hline 11 & peba & - & extinta & lista léxica \\
\hline 12 & morike & - & extinta & lista léxica \\
\hline 13 & mabenaro & - & extinta & lista léxica \\
\hline 14 & culli & - & extinta & lista léxica \\
\hline 15 & arazaire $^{3}$ & - & ¿extinta? & lista léxica \\
\hline 16 & $\begin{array}{l}\text { quechua de Santa Ana de } \\
\text { Tusi (Pasco) }\end{array}$ & qxt & moribunda & comparativo \\
\hline 17 & $\begin{array}{l}\text { quechua de Chiquián } \\
\text { (Áncash) }\end{array}$ & qxa & moribunda & comparativo \\
\hline 18 & quechua clásico & qwe & extinta & texto \\
\hline 19 & maynas jesuítico & - & extinta & texto \\
\hline 20 & aewa & ash & extinta & fonología \\
\hline 21 & $\begin{array}{l}\text { lengua de señas de } \\
\text { Inmaculada }\end{array}$ & - & amenazada & comparativo \\
\hline 22 & huachipaeri & hug & casi extinta & fonología \\
\hline 23 & mashco piro & cuj & amenazada & lista léxica \\
\hline
\end{tabular}

3 Renzo Ego Aguirre (en comunicación personal) reporta que ha tomado contacto con dos hablantes de arazaire, por lo que se trataría de una lengua casi extinta, aunque se la reporte como lengua extinta. Incluimos signos de interrogación y volvemos al tema del arazaire más abajo 


\begin{tabular}{|c|c|c|c|c|}
\hline Prioridad & Lengua & ISO $639-3$ & Amenaza & Descripción \\
\hline 24 & andoa & anb & extinta & rasgo específico \\
\hline 25 & yameo & yme & extinta & bosquejo gramatical \\
\hline 26 & $\begin{array}{l}\text { quechua de Cajatambo } \\
\text { (Lima) }\end{array}$ & qvl & moribunda & rasgo específico \\
\hline 27 & $\begin{array}{l}\text { quechua de Yanahuanca } \\
\text { (Pasco) }\end{array}$ & qur & en reemplazo & fonología \\
\hline 28 & puquina & puq & extinta & bosquejo gramatical \\
\hline 29 & panobo & pno & extinta & bosquejo gramatical \\
\hline 30 & nonuya & noj & extinta & bosquejo gramatical \\
\hline 31 & ashéninka Pajonal & cjo & amenazada & texto \\
\hline 32 & chamicuro & $\mathrm{ccc}$ & casi extinta & diccionario \\
\hline 33 & taushiro & $\operatorname{trr}$ & casi extinta & bosquejo gramatical \\
\hline 34 & quechua de Puno & qxp & no en peligro & texto \\
\hline 35 & quechua de Chincha & qxc & extinta & gramática \\
\hline 36 & maijiki & ore & casi extinta & bosquejo gramatical \\
\hline 37 & omagua & omg & casi extinta & bosquejo gramatical \\
\hline 38 & mochica & $\mathrm{omc}$ & extinta & gramática \\
\hline 39 & muniche & myr & casi extinta & bosquejo gramatical \\
\hline 40 & iñapari & inp & casi extinta & bosquejo gramatical \\
\hline 41 & witoto nüpode & hux & moribunda & diccionario \\
\hline 42 & cholón & cht & extinta & gramática \\
\hline 43 & arabela & arl & casi extinta & bosquejo gramatical \\
\hline 44 & cauqui & - & casi extinta & bosquejo gramatical \\
\hline 45 & resígaro & rgr & casi extinta & gramática \\
\hline 46 & $\begin{array}{l}\text { quechua de Panao } \\
\text { (Huánuco) }\end{array}$ & qxh & moribunda & bosquejo gramatical \\
\hline 47 & quechua de Pacaraos & qvp & moribunda & bosquejo gramatical \\
\hline 48 & $\begin{array}{l}\text { quechua de Margos- } \\
\text { Yarowilca-Lauricocha } \\
\text { (Huánuco) }\end{array}$ & qvm & amenazada & rasgo específico \\
\hline 49 & $\begin{array}{l}\text { quechua de Huamalíes- } \\
\text { Dos de Mayo (Huánuco) }\end{array}$ & qvh & amenazada & rasgo específico \\
\hline
\end{tabular}




\begin{tabular}{|c|c|c|c|c|}
\hline Prioridad & Lengua & ISO $639-3$ & Amenaza & Descripción \\
\hline 50 & $\begin{array}{l}\text { quechua de Huangascar- } \\
\text { Topara-Yauyos }\end{array}$ & qux & casi extinta & gramática \\
\hline 51 & lengua de señas peruana & prl & en reemplazo & diccionario \\
\hline 52 & ocaina & oca & casi extinta & gramática \\
\hline 53 & capanahua & $\mathrm{kaq}$ & moribunda & bosquejo gramatical \\
\hline 54 & jebero & jeb & casi extinta & gramática \\
\hline 55 & isconahua & isc & casi extinta & gramática \\
\hline 56 & iquito & iqu & casi extinta & gramática \\
\hline 57 & cocama-cocamilla & $\operatorname{cod}$ & casi extinta & gramática \\
\hline 58 & quechua shausha huanca & qxw & moribunda & gramática \\
\hline 59 & quechua de San Martín & qvs & moribunda & gramática \\
\hline 60 & quechua de Chachapoyas & quk & en reemplazo & bosquejo gramatical \\
\hline 61 & nomatsiguenga & not & en reemplazo & bosquejo gramatical \\
\hline 62 & machiguenga & $\mathrm{mcb}$ & en reemplazo & bosquejo gramatical \\
\hline 63 & candoshi-shapra & $\mathrm{cbu}$ & en reemplazo & bosquejo gramatical \\
\hline 64 & amahuaca & amc & moribunda & gramática \\
\hline 65 & yagua & yad & en reemplazo & gramática \\
\hline 66 & urarina & ura & en reemplazo & gramática \\
\hline 67 & secoya & sey & en reemplazo & gramática \\
\hline 68 & $\begin{array}{l}\text { quechua del sur de } \\
\text { Conchucos (Áncash) }\end{array}$ & qxo & amenazada & bosquejo gramatical \\
\hline 69 & $\begin{array}{l}\text { quechua de Sihuas } \\
\text { (Áncash) }\end{array}$ & qws & amenazada & bosquejo gramatical \\
\hline 70 & $\begin{array}{l}\text { quichua del norte de } \\
\text { Pastaza }\end{array}$ & qvz & amenazada & bosquejo gramatical \\
\hline 71 & quichua del Napo & qvo & amenazada & bosquejo gramatical \\
\hline 72 & quechua de Cajamarca & $\mathrm{qvc}$ & en reemplazo & gramática \\
\hline 73 & quechua de Ambo-Pasco & qva & amenazada & bosquejo gramatical \\
\hline 74 & quechua de Lambayeque & quf & en reemplazo & gramática \\
\hline 75 & yine & pib & en reemplazo & gramática \\
\hline 76 & matsés & $\mathrm{mcf}$ & en reemplazo & gramática \\
\hline
\end{tabular}




\begin{tabular}{|c|c|c|c|c|}
\hline Prioridad & Lengua & ISO $639-3$ & Amenaza & Descripción \\
\hline 77 & jaqaru & jqr & en reemplazo & gramática \\
\hline 78 & witoto murui & huu & en reemplazo & gramática \\
\hline 79 & huambisa & hub & en reemplazo & gramática \\
\hline 80 & ese eja & ese & en reemplazo & gramática \\
\hline 81 & culina & cul & en reemplazo & gramática \\
\hline 82 & $\begin{array}{l}\text { ashéninka de } \\
\text { Ucayali-Yurúa }\end{array}$ & $\mathrm{cpb}$ & amenazada & bosquejo gramatical \\
\hline 83 & caquinte & $\cot$ & en reemplazo & gramática \\
\hline 84 & asháninka & $\mathrm{cni}$ & amenazada & bosquejo gramatical \\
\hline 85 & shawi & $\mathrm{cbt}$ & amenazada & bosquejo gramatical \\
\hline 86 & cashinahua & cbs & en reemplazo & gramática \\
\hline 87 & cashibo-cacataibo & $\mathrm{cbr}$ & en reemplazo & gramática \\
\hline 88 & amarakaeri & $\mathrm{amr}$ & en reemplazo & gramática \\
\hline 89 & yanesha' & ame & en reemplazo & gramática \\
\hline 90 & achuar-shiwiar & $\mathrm{acu}$ & en reemplazo & gramática \\
\hline 91 & yaminahua & yaa & amenazada & gramática \\
\hline 92 & ticuna & tca & amenazada & gramática \\
\hline 93 & $\begin{array}{l}\text { castellano de } \\
\text { Loreto-Ucayali }\end{array}$ & spq & no en peligro & bosquejo gramatical \\
\hline 94 & shipibo-conibo & shp & amenazada & gramática \\
\hline 95 & $\begin{array}{l}\text { quechua de Arequipa- } \\
\text { La Unión }\end{array}$ & qxu & no en peligro & bosquejo gramatical \\
\hline 96 & $\begin{array}{l}\text { quechua del norte de } \\
\text { Conchucos (Áncash) }\end{array}$ & qxn & amenazada & gramática \\
\hline 97 & $\begin{array}{l}\text { quechua de Huaylas } \\
\text { (Áncash) }\end{array}$ & qwh & amenazada & gramática \\
\hline 98 & $\begin{array}{l}\text { quechua de Corongo } \\
\text { (Áncash) }\end{array}$ & qwa & amenazada & gramática \\
\hline 99 & quechua huaylla huanca & qvw & no en peligro & bosquejo gramatical \\
\hline 100 & $\begin{array}{l}\text { quechua del norte de } \\
\text { Junín }\end{array}$ & qvn & amenazada & gramática \\
\hline 101 & $\begin{array}{l}\text { quechua del este de } \\
\text { Apurímac }\end{array}$ & qve & no en peligro & bosquejo gramatical \\
\hline
\end{tabular}




\begin{tabular}{|c|c|c|c|c|}
\hline Prioridad & Lengua & ISO 639-3 & Amenaza & Descripción \\
\hline 102 & quechua de Cuzco & quz & amenazada & gramática \\
\hline 103 & quechua del sur de Pastaza & qup & no en peligro & bosquejo gramatical \\
\hline 104 & $\begin{array}{l}\text { quechua del Huallaga } \\
\text { (Huánuco) }\end{array}$ & qub & amenazada & gramática \\
\hline 105 & ashéninka del Perené & prq & amenazada & gramática \\
\hline 106 & yora & mts & no en peligro & bosquejo gramatical \\
\hline 107 & sharanahua & $\operatorname{mcd}$ & amenazada & gramática \\
\hline 108 & lengua de señas de Sivia & lsv & amenazada & gramática \\
\hline 109 & ashéninka de Pichis & cpu & amenazada & gramática \\
\hline 110 & ajyíninka del Apurucayali & $\mathrm{cpc}$ & amenazada & gramática \\
\hline 111 & nanti & $\operatorname{cox}$ & amenazada & gramática \\
\hline 112 & bora & boa & amenazada & gramática \\
\hline 113 & aimara central & ayr & amenazada & gramática \\
\hline 114 & aguaruna & agr & amenazada & gramática \\
\hline 115 & quechua de Ayacucho & quy & no en peligro & gramática \\
\hline 116 & aimara sureño & ayc & no en peligro & gramática \\
\hline
\end{tabular}

El mapa en la Figura 3 presenta los datos de la Tabla 10 siguiendo el sistema de representación de GlottoVis. Básicamente, cada estatus de vitalidad es representado con un color y cada grado de descripción con una forma diferente. El resultado es un mapa en el que es posible visualizar ambas variables al mismo tiempo para todas las lenguas peruanas en Glottolog.

Si dejamos de lado a las lenguas extintas con las que, lamentablemente, ya no se puede hacer trabajo descriptivo intensivo, la Tabla 10 muestra que, de acuerdo con los datos de Glottolog (que se encuentran en constante revisión), 40 lenguas de vitalidad baja (amenazadas, en reemplazo, moribundas y casi extintas) no cuentan con gramáticas comprehensivas. La cifra subiría a 41 si retiráramos al arazaire de la lista de lenguas sin hablantes (ver nota al pie 3). La documentación y descripción de estas 40 o 41 lenguas deberían ser una prioridad en el trabajo lingüístico en el Perú. 
Figura 3. Las lenguas de Perú con AES y nivel de descripción en mapa

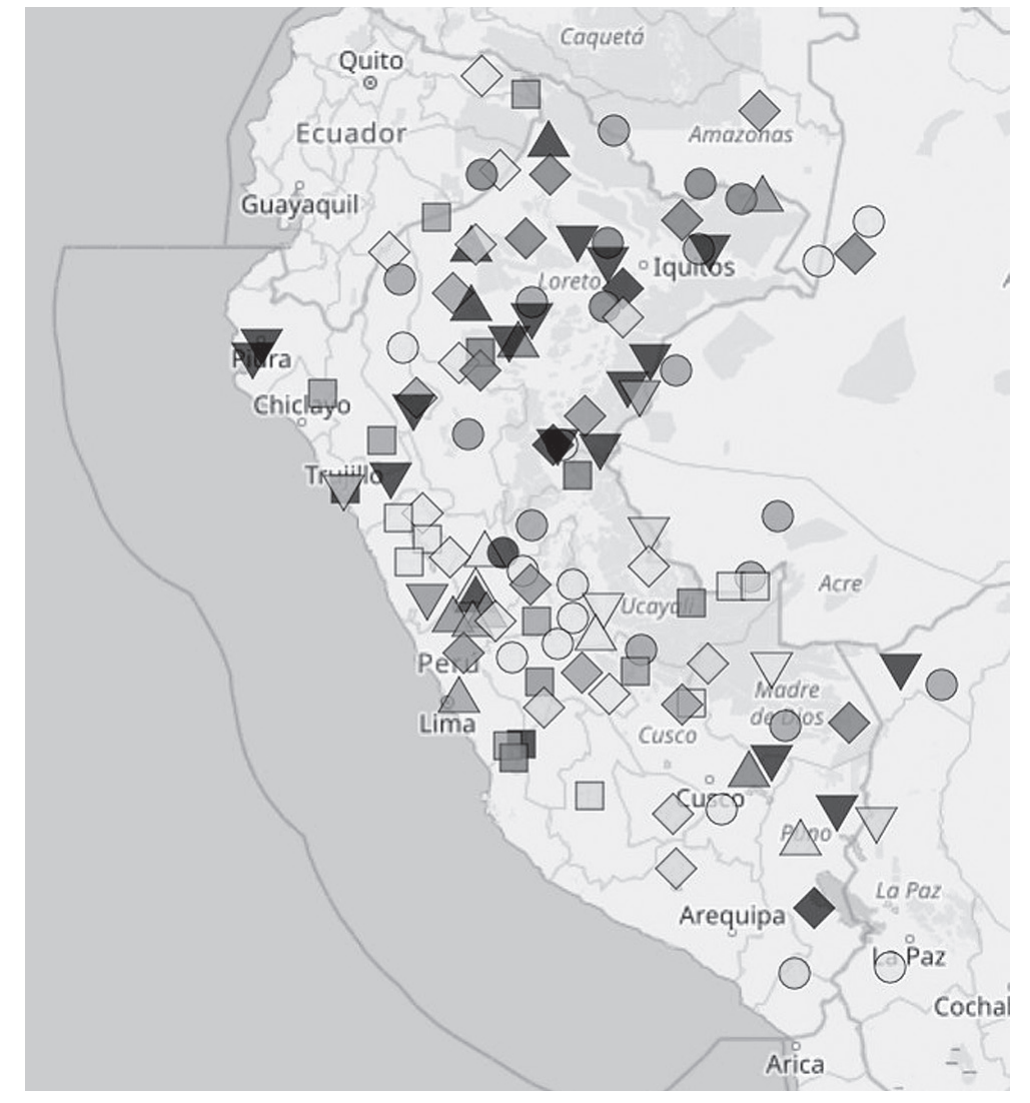

\begin{tabular}{|c|c|c|c|c|c|c|c|}
\hline & $\begin{array}{l}\text { La lengua se } \\
\text { no en peligro }\end{array}$ & $\begin{array}{l}\text { ncuentra... } \\
\text { amenazada }\end{array}$ & en reemplazo & moribunda & casi extinta & extinta & total \\
\hline $\begin{array}{l}\text { La descripción más } \\
\text { extensiva es... }\end{array}$ & 0 & O & O & ○ & 0 & \multicolumn{2}{|l|}{ - } \\
\hline gramática larga & 3 & 11 & 11 & 1 & 5 & 1 & 32 \\
\hline gramática & 1 & 6 & 7 & 2 & 3 & 2 & 21 \\
\hline bosquejo gramatical & 6 & 9 & 5 & 3 & 6 & 3 & 32 \\
\hline fonología/textos & 1 & 4 & 2 & 3 & 2 & 4 & 16 \\
\hline lista léxica o menos & 3 & 1 & 1 & 1 & 0 & 18 & 22 \\
\hline total & 14 & 31 & 26 & 10 & 16 & 26 & 123 \\
\hline
\end{tabular}

Nota. Obtenido de Hammarström, Forkel y Haspelmath (2018): https://glottolog.org/ langdoc/status/browser?country= $\mathrm{PE}$ 
Veamos estas cifras con más detalle. En primer lugar, tenemos a aquellas lenguas para las que no se cuenta siquiera con un bosquejo gramatical. En el Perú, de acuerdo con los datos de Glottolog, 14 lenguas se encuentran en esa situación. Y de estas 14 lenguas 6 se encuentran en estado crítico (casi extintas o moribundas). Nuevamente, de confirmarse el reporte mencionado en la nota al pie 3, deberíamos incluir además al arazaire, por lo que el número subiría a 15, con 7 lenguas en estado crítico no descritas. Estas lenguas deberían ser catalogadas como de prioridad máxima. Esto se aprecia claramente en la Tabla 11.

Tabla 11. Lenguas peruanas sin gramáticas ni bosquejos gramaticales ordenada de acuerdo a su grado de amenaza

\begin{tabular}{|c|c|c|c|}
\hline Lengua & $\begin{array}{l}\text { ISO } \\
639-3\end{array}$ & Amenaza & Descripción \\
\hline arazaire & - & ¿extinta? & lista léxica \\
\hline huachipaeri & hug & casi extinta & fonología \\
\hline chamicuro & $\operatorname{ccc}$ & casi extinta & diccionario \\
\hline witoto nüpode & hux & moribunda & diccionario \\
\hline quechua de Chiquián (Áncash) & qxa & moribunda & $\begin{array}{l}\text { estudio } \\
\text { comparativo }\end{array}$ \\
\hline quechua de Santa Ana de Tusi (Pasco) & qxt & moribunda & $\begin{array}{l}\text { estudio } \\
\text { comparativo }\end{array}$ \\
\hline quechua de Cajatambo (Lima) & qvl & moribunda & rasgo específico \\
\hline quechua de Yanahuanca (Pasco) & qur & en reemplazo & fonología \\
\hline lengua de señas peruana & prl & en reemplazo & diccionario \\
\hline lengua de señas de Inmaculada & - & amenazada & $\begin{array}{l}\text { estudio } \\
\text { comparativo }\end{array}$ \\
\hline mashco piro & cuj & amenazada & lista léxica \\
\hline $\begin{array}{l}\text { quechua de Huamalíes-Dos de Mayo } \\
\text { (Huánuco) }\end{array}$ & qvh & amenazada & rasgo específico \\
\hline $\begin{array}{l}\text { quechua de Margos-Yarowilca- } \\
\text { Lauricocha (Huánuco) }\end{array}$ & qvm & amenazada & rasgo específico \\
\hline ashéninka del Pajonal & cjo & amenazada & texto \\
\hline quechua de Puno & qxp & no en peligro & texto \\
\hline
\end{tabular}


Además de estas 15 lenguas peruanas, otras 26 solo llegan al grado de descripción de bosquejo gramatical. Es decir, solo contamos con una descripción gramatical superficial. Estas lenguas también son de prioridad alta y, de entre ellas, la descripción de las 9 lenguas catalogadas como casi extintas o moribundas es urgente. Esto se resume en la Tabla 12.

Tabla 12. Lenguas peruanas solo con bosquejos gramaticales ordenadas de acuerdo a su grado de amenaza

\begin{tabular}{llll}
\hline Lengua & ISO 639-3 & Amenaza & Descripción \\
\hline omagua & omg & casi extinta & bosquejo \\
muniche & myr & casi extinta & bosquejo gramatical \\
iñapari & inp & casi extinta & bosquejo gramatical \\
arabela & arl & casi extinta & bosquejo gramatical \\
maijiki & ore & casi extinta & bosquejo gramatical \\
taushiro & trr & casi extinta & bosquejo gramatical \\
quechua de Pacaraos & qvp & moribunda & bosquejo gramatical \\
quechua de Panao (Huánuco) & qxh & moribunda & bosquejo gramatical \\
kapanawa & kaq & moribunda & bosquejo gramatical \\
nomatsiguenga & not & en reemplazo & bosquejo gramatical \\
machiguenga & mcb & en reemplazo & bosquejo gramatical \\
kandoshi-shapra & cbu & en reemplazo & bosquejo gramatical \\
quechua del sur de Conchucos & qxo & amenazada & bosquejo gramatical \\
(Áncash) & & & \\
quichua del norte de Pastaza & qvz & amenazada & bosquejo gramatical \\
quechua de Sihuas (Áncash) & qws & amenazada & bosquejo gramatical \\
quechua del Napo & qvo & amenazada & bosquejo gramatical \\
quechua de Ambo (Pasco) & qva & amenazada & bosquejo gramatical \\
ashéninka del Ucayali-Yurúa & cpb & amenazada & bosquejo gramatical \\
asháninka & cni & amenazada & bosquejo gramatical \\
shawi & cbt & amenazada & bosquejo gramatical \\
castellano de Loreto-Ucayali & spq & no en peligro & bosquejo gramatical \\
\hline
\end{tabular}




\begin{tabular}{llll}
\hline Lengua & ISO 639-3 & Amenaza & Descripción \\
\hline quechua de Arequipa-La Unión & qxu & no en peligro & bosquejo gramatical \\
quechua de Huaylla-Huanca & qvw & no en peligro & bosquejo gramatical \\
quechua del este de Apurímac & qve & no en peligro & bosquejo gramatical \\
quechua del sur de Pastaza & qup & no en peligro & bosquejo gramatical \\
yora & mts & no en peligro & bosquejo gramatical \\
\hline
\end{tabular}

El resto de lenguas peruanas listadas en Glottolog cuenta con una gramática y, en ese sentido, a primera vista, presentarían una prioridad de estudio más baja. Sin embargo, en muchos casos, esto es solo aparente. Las gramáticas de lenguas peruanas difieren mucho en términos de su extensión y calidad. Una parte de ellas fue escrita empleando bases empíricas débiles y/o marcos teóricos hoy obsoletos. Además, muchas no son necesariamente comprehensivas. En realidad, muchas de las gramáticas de lenguas peruanas requieren de urgentes desarrollos o incluso necesitarían ser rescritas. Si bien una reseña crítica de cada una de las gramáticas de lenguas peruanas excede el objetivo de este estudio, en $\$ 4$, avanzamos algunas propuestas con respecto a ello y ofrecemos una caracterización un poco más detallada de las gramáticas de lenguas peruanas disponibles.

\section{La gramaticografía contemporánea y las lenguas peruanas}

En esta sección, ofrecemos algunos comentarios más detallados sobre las gramáticas de lenguas peruanas desde la perspectiva de los postulados de la gramaticografía contemporánea. De acuerdo a Glottolog, existen 96 referencias bibliográficas sobre lenguas peruanas que pueden ser catalogadas como gramáticas. Sin embargo, una rápida revisión de las fuentes disponibles muestran su gran diversidad. Algunas de estas gramáticas superan las 1000 páginas y otras bordean las 100. Algunas se enfocan en la morfología y/o la fonología, y otras cubren distintas áreas de la gramática, incluyendo discusiones sobre discurso y estructura de la información. Algunas tienen un carácter pedagógico y otras, uno puramente académico. 
Algunas se enmarcan en modelos teóricos muy estrechos y otras asumen una perspectiva funcional y tipológica más general.

En la Tabla 13, encontramos la lista de referencias sobre lenguas peruanas catalogadas como gramáticas en Glottolog ordenadas de acuerdo a su número de páginas. ${ }^{4}$ La gramática más extensa de cualquier lengua peruana escrita hasta la fecha es la gramática del matsés (pano) de Fleck (2003) y la más breve es la gramática del quechua de Huaylas de Escribens y Proulx (1970).

Tabla 13. Gramáticas de lenguas peruanas organizadas por su extensión

\begin{tabular}{lll}
\hline Referencia & Lengua & \# páginas \\
\hline Fleck (2003) & matsés & xxi+1257 \\
Valenzuela (2003) & shipibo-conibo & xxxiv+1029 \\
Peña (2015) & wampis & xl+931 \\
Olawsky (2006) & urarina & xviii+943 \\
Vallejos (2010) & kukama-kukamiria & xxix+918 \\
Tschudi (1853) & quechua & iv+268+vi+110+ \\
Soares (1992) & ticuna & viii+507 \\
Zariquiey (2011) & kakataibo & iv+242+ii+648 \\
Coler (2014) & aimara muylaq' & xxviii+857 \\
Vallejos (2016) & kukama-Kukamiria & xvi+755 +775 \\
Vuillermet (2012) & ese eja & xvi+736 \\
Dienst (2006) & kulina & 740 \\
Mihas (2015) & ashéninka & xxvii+682 \\
Zariquiey (2018) & kakataibo & xxx+668 \\
Overall (2017) & awajún & xxvi+636 \\
Weber (1996) & quechua del Huallaga & 641 \\
Wojtylak (2017) & murui $^{5}$ & xxiv+613 \\
\hline
\end{tabular}

Ver Hammarström, Forkel y Haspelmath (2018) para más detalles.

5 La variedad de Brasil.

6 La variedad de Bolivia.

7 La variedad de Brasil. 


\begin{tabular}{|c|c|c|}
\hline Referencia & Lengua & \# páginas \\
\hline Lai (2009) & iquito & xviii +611 \\
\hline Overall (2007) & awajún & xxii +588 \\
\hline Thiesen y Weber (2012) & bora & xxxiii +550 \\
\hline Tschudi (1884) & quechua & xvi +535 \\
\hline Allin (1976) & resígaro & $x+533$ \\
\hline Helberg Chávez (1984) & amarakaeri & $x x x+518$ \\
\hline Alexander-Bakkerus (2005) & cholón & 533 \\
\hline Coler (2010) & aimara muylaq' & xvii +515 \\
\hline Weber (1989) & quechua del Huallaga & $\mathrm{xxv}+490$ \\
\hline Adelaar (1977) & quechua de Tarma & 510 \\
\hline Wexler (1967) & $\operatorname{aimara}^{8}$ & xvi+486 \\
\hline Payne (1989) & ashéninka & 502 \\
\hline Weber (1983) & quechua del Huallaga & xvii +455 \\
\hline Michael (2008) & nanti & $x x v+462$ \\
\hline Matteson (1965) & yine & $x+467$ \\
\hline Fernández (1872) & quechua cuzqueño & $\mathrm{xvi}+441+9$ \\
\hline Calvo (1993) & quechua cuzqueño & 475 \\
\hline Fagua (2013) & ocaina & 473 \\
\hline Camargo (1991) & kashinawa & xiii +458 \\
\hline Tarifa (1970) & $\operatorname{aimara}^{9}$ & 453 \\
\hline Payne (1985) & yagua & 441 \\
\hline Porterie-Gutiérrez (1992) & $\operatorname{aimara}^{10}$ & 431 \\
\hline Anderson $(1962 / 1980)$ & ticuna & $x x v+402$ \\
\hline Hanson (2010) & yine & $x x i+391$ \\
\hline Hardman, Vásquez y Yapita (2001) & $\operatorname{aimara}^{11}$ & 393 \\
\hline Black, Bolli y Ticsi (1990) & quechua Junín-Pasco & 406 \\
\hline
\end{tabular}

8 La variedad de Bolivia.

La variedad de Bolivia.

10 La variedad de Bolivia.

11 La variedad de Bolivia. 


\begin{tabular}{|c|c|c|}
\hline Referencia & Lengua & \# páginas \\
\hline Seifart (2005) & bora & xiii +375 \\
\hline Guardia (1973) & quechua cuzqueña & 388 \\
\hline Corbera Mori (1994) & awajún & 385 \\
\hline Huayhua Pari (2001) & aimara & xiv +365 \\
\hline Howkins (1977) & quechua de San Martín & $x i+363$ \\
\hline Middendorf (1970) & quechua cuzqueño & xxiv +345 \\
\hline Clark (2017) & lengua de señas de Sivia & $\mathrm{xxii}+340$ \\
\hline Bertonio (1603) & aimara & 360 \\
\hline Shimelman (2017) & quechua de Yauyos & 359 \\
\hline Middendorf (1890) & quechua cuzqueño & vii +339 \\
\hline Mihas (2010) & ashéninka & xiv +321 \\
\hline González Holguín (1842 [1607]) & quechua cuzqueño & 330 \\
\hline Dienst (2014) & kulina $^{12}$ & $\mathrm{xix}+307$ \\
\hline Tiss (2004) & kulina $^{13}$ & 324 \\
\hline Kaxinawá (2014) & kashinawa $^{14}$ & 323 \\
\hline Payne, Payne y Sánchez (1982) & ashéninka (Apurucayali) & 311 \\
\hline Cusihuamán (1976) & quechua Cuzco-Collao & 306 \\
\hline Santo Thomas (1560) & quechua chinchay & xviii+97+viii +180 \\
\hline Payne (1981) & ashéninka (Apurucayali) & $\mathrm{ix}+285$ \\
\hline Deza Galindo (1992) & aimara & 294 \\
\hline Payne (1978) & ashéninka (Apurucayali) & viii +285 \\
\hline Zariquiey y Córdova (2008) & quechua chanka & 288 \\
\hline Duff-Tripp (1997) & yánesha & 283 \\
\hline Cerrón-Palomino (1976) & quechua Junín-Huanca & 283 \\
\hline Sola y Parker (1963) & quechua ayacuchano & 282 \\
\hline Grajeda y Vela Flores (1976) & quechua cuzqueño & 273 \\
\hline Hardman (1983) & jaqaru & 266 \\
\hline
\end{tabular}

12 La variedad de Brasil.

13 La variedad de Brasil.

14 La variedad de Brasil. 
Zariquiey et al. • Obsolescencia lingüística, descripción gramatical y documentación...

\begin{tabular}{|c|c|c|}
\hline Referencia & Lengua & \# páginas \\
\hline Hardman (2001) & $\operatorname{aimara}^{15}$ & $\mathrm{xiv}+250$ \\
\hline Matteson (1963) & yine & $v i+255$ \\
\hline Hintz y Ballena (2000) & quechua de Corongo & 261 \\
\hline Mata (2007 [1748]) & cholón & 257 \\
\hline Staly, Davis y Kneeland (1979) & matsés & 250 \\
\hline Santo Thomas (1995 [1560]) & quechua chinchay & lxvi+179 \\
\hline Middendorf (1892) & quechua cuzqueño & 244 \\
\hline Samanez (1996) & quechua cuzqueño & 235 \\
\hline Swift (1985) & caquinte & xiv +216 \\
\hline Thoron (1886) & quechua cuzqueño & 229 \\
\hline Payne y Payne (1990) & yagua & 225 \\
\hline Zariquiey (2015) & iskonawa & 224 \\
\hline Weber, Coombs y Coombs (1976) & quechua de San Martín & 222 \\
\hline Grondin Nadon (1999 [1985]) & $\operatorname{aimara}^{16}$ & 218 \\
\hline Townsend, Ballena y Swift (1988) & caquinte & 216 \\
\hline Itier (1997) & quechua cuzqueño & 208 \\
\hline Shimelman (2014) & quechua del sur de Yauyos & 206 \\
\hline Eakin (1991) & yaminawa & 194 \\
\hline Alviano (1944) & ticuna $^{17}$ & 191 \\
\hline Cunha (1993) & sharanawa ${ }^{18}$ & 191 \\
\hline Quesada (1976) & quechua Cajamarca-Cañaris & 190 \\
\hline Montes Rodríguez (2004) & ticuna $^{19}$ & 188 \\
\hline Park y Wyss (1995) & quechua de San Martín & $48+63+77$ \\
\hline Parker (1976) & quechua Áncash-Huailas & ii +185 \\
\hline Soares (2000) & ticuna ${ }^{20}$ & 185 \\
\hline Soto-Ruiz (1976) & qechua Ayacucho-Chanca & 182 \\
\hline
\end{tabular}

15 La variedad de Bolivia.

16 La variedad de Bolivia.

17 La variedad de Brasil.

18 La variedad de Brasil.

19 La variedad de Colombia

20 La variedad de Brasil. 


\begin{tabular}{|c|c|c|}
\hline Referencia & Lengua & \# páginas \\
\hline Bendor-Samuel (1979) & shiwilu & 179 \\
\hline Souza (2012) & sharanawa ${ }^{21}$ & 177 \\
\hline Faust y Loos (2002) & yaminawa & 174 \\
\hline Faust (1978) & kukama kukamiria & 173 \\
\hline Faust (1972) & kukama kukamiria & 173 \\
\hline Taylor (1999) & quechua de Ferreñafe & 172 \\
\hline Hoggarth (2004) & quechua cuzqueño & 168 \\
\hline Montag (1979) & kashinawa & 165 \\
\hline Sola y Parker (1964) & quechua ayacuchano & xii +149 \\
\hline Faust (1973) & shipibo-konibo & 160 \\
\hline Wroughton (1996) & quechua huanca & 151 \\
\hline Taylor (1996) & quechua de Ferreñafe & 144 \\
\hline Hardman (2000) & jaqaru & 138 \\
\hline Hardman (1966) & jaqaru & 138 \\
\hline Soto-Ruiz (1979) & quechua ayacuchano & 133 \\
\hline Thiesen (2008) & bora & 132 \\
\hline Thiesen (1996) & bora & 132 \\
\hline Parker (1965) & quechua ayacuchano & 126 \\
\hline Johnson y Levinsohn (1990) & $\operatorname{secoya}^{22}$ & 113 \\
\hline Wroughton (1988) & quechua de Conchucos & 110 \\
\hline Russell (1975) & amawaka & 108 \\
\hline Escribens y Proulx (1970) & quechua de Huaylas & 85 \\
\hline
\end{tabular}

Es importante indicar que el criterio de extensión no es equivalente al de calidad ni al de exhaustividad o comprehensividad. Sin embargo, ofrece una referencia automática precisa que al menos indirectamente se relaciona con el potencial de un estudio gramatical para cubrir un mayor número de tópicos tipológicos con cierto detalle. Entonces, la extensión —expresada en el número de

$21 \quad$ La variedad de Brasil.

22 La variedad de Ecuador. 
páginas - es solamente un indicador relativo para medir uno de los criterios que definen la gramaticografía contemporánea: las gramáticas deben ser comprehensivas (Noonan 2006; Rice 2006). Definir comprehensivo al hablar de gramáticas referenciales no es una tarea libre de subjetividades. La idea es que el lector debería encontrar información sobre la fonética, la fonología, la morfología, la sintaxis y la estructura del discurso. Para Noonan (2006), una gramática comprehensiva debería contener, además, información sobre las filiaciones genéticas y areales de la lengua, sobre su contexto sociolingüístico y cultural, y sobre la literatura previa sobre la lengua y la familia lingüística a la que esta pertenece. Se recomienda también que las gramáticas contengan un diccionario por lo menos mínimo y, dado los avances tecnológicos recientes, que incluyan información sobre algunos aspectos fonéticos relevantes. Si bien no es siempre el caso que todos estos aspectos se hayan desarrollado en las gramáticas disponibles, para Noonan (2006), mientras más de estos aspectos estén cubiertos, más comprehensiva será la gramática. Ciertamente, la extensión suele ir de la mano con este aspecto, pero debe de tomarse como una variable solo referencial, ya que no todas las gramáticas extensas satisfacen igualmente todos los criterios que Noonan emplea para definir gramática comprebensiva.

Una gramática que siga los lineamientos de la gramaticografía contemporánea debería, además, tener una base empírica sólida, manifiesta en un trabajo de campo prolongado y ético que sirva de base para la incorporación de ejemplos naturales. El uso de ejemplos naturales es un aspecto central para la gramaticografía contemporánea. De los ejemplos, se espera que estén adecuadamente glosados y traducidos, y que ilustren todos los aspectos descritos en la gramática. Un asunto cada vez más importante tiene que ver con la accesibilidad al ejemplo. En la actualidad, se espera que los ejemplos empleados en una gramática provengan de usos reales, grabados cuidadosamente y archivados en una base de datos que debería ser públicamente accesible. Los ejemplos elicitados en sesiones de traducción a partir de una lengua nacional como el 
castellano, el portugués o el inglés deben ser empleados con cautela y no deberían ser mayoritarios en una descripción gramatical.

Una gramática debe, finalmente, dialogar de forma creativa y productiva con un marco teórico sólido (usualmente vinculado a lo que se llama lingüística tipológico-funcional) y argumentar correctamente los análisis presentados en el marco de dicha teoría. La tipología contemporánea ha hecho avances significativos en el estudio del lenguaje y estos avances traen nuevas preguntas. Responderlas debería ser también algo central para la tarea gramaticográfica. Para comprender un poco mejor la evolución de la relación entre teoría y descripción gramatical de lenguas peruanas, hemos examinado los términos utilizados en dichas gramáticas a lo largo del tiempo. El objetivo es identificar los términos que caracterizan los diversos momentos de la producción gramaticográfica sobre lenguas peruanas.

Para ello, hemos agrupado las fuentes en periodos de 20 años, y por cada periodo hemos calculado los términos con la medición TF-IDF (una técnica estándar de las ciencias de la computación; ver por ejemplo Manning, Raghavan y Schütze 2008). Los fulltext de las fuentes estudiadas están disponibles desde el proyecto DReaM..$^{23} \mathrm{La}$ Tabla 14 muestra los 20 términos más usados para cada periodo de años en las gramáticas de lenguas peruanas escritas en inglés. ${ }^{24} \mathrm{Nues}-$ tros hallazgos muestran que las gramáticas de los años 1940-1960 se caracterizan por términos como grammeme, hypergrammeme, uttereme, etc. y abreviaturas como VCT, VCI, etc.). Todos estos términos provienen de la teoría tagmémica (Pike 1967). En la actualidad, la tagmémica constituye un marco teórico obsoleto que ya no se enseña y ya no se usa en la producción de nuevo conocimiento lingüístico. Las fuentes insertas en este marco teórico son prácticamente inútiles para la comparación tipológica moderna o

23 Dictionary/Grammar Reading Machine: Computational Tools for Accessing the World's Linguistic Heritage (DReaM), proyecto financiado por el Joint Programming Initiative in Cultural Heritage and Global Change, Digital Heritage y Riksantikvarieämbetet, Suecia.

24 Lamentablemente, las fuentes escritas en castellano son demasiado pocas y no manifiestan diferencias estadísticas claras a lo largo del tiempo. 
para cualquier otra empresa lingüística contemporánea y simplemente necesitan reescribirse. La influencia de la tagmémica en las gramáticas de lenguas peruanas, sin embargo, continuó durante el periodo 1960-1980, aunque ya para entonces se empiezan a instaurar modelos descriptivos más generales y contemporáneos, tal como se aprecia en algunos de los términos y abreviaturas más usadas en esa época. En el periodo 1980-2000, empiezan a aparecer más sistemáticamente las abreviaturas gramaticales características de los ejemplos glosados contemporáneos, así como varios términos de la lingüística tipológico-funcional moderna, tales como evidential, adverbial, discourse, etc. El último periodo (2000-2019) se ve dominado ya por abreviaturas gramaticales típicas de los ejemplos interlinearizados y glosados, característicos de las descripciones modernas. Lo que muestra la tabla es, entonces, una forma de entender el devenir de la tradición gramaticográfica sobre lenguas peruanas, en la que un modelo muy particular de análisis lingüístico ha ido dando paso a la incorporación de una visión tipológica más general y contemporánea.

Entonces, es, ya entrada la década de 1980, que se empieza a instaurar una gramaticografía moderna de base tipológica en la tradición descriptiva sobre lenguas peruanas. Esto se aprecia en la Figura 4, en donde ilustramos la distribución temporal de algunos términos de la tipología contemporánea, tales como applicative, classifier, clitic, evidentiality, frustrative y converb en la descripción de lenguas peruanas. Tal como podemos apreciar, los picos más tempranos en el uso de estos términos se ubican alrededor de la década de 1980.

Lo que nuestros experimentos parecen sugerir es que es bastante probable que varias de las gramáticas de lenguas peruanas escritas antes de la década de 1980 no estén en línea con los postulados de la gramaticografía ni la tipología contemporáneas y requieran de revisiones, reevaluaciones o, en algunos casos, de un proceso total de reescritura. Esta afirmación no es un juicio de valor sobre la calidad de las gramáticas. Muy por el contrario, varias de las gramáticas más tempranas (incluso algunos trabajos coloniales) son verdaderos ejemplos de trabajos descriptivos de su época y deben ser valorados en el contexto del tiempo en que fueron escritos. 
Tabla 14. Los veinte términos más recurrentes por medida de TF-IDF en las gramáticas de lenguas peruanas escritas en inglés durante 1940-2020

\begin{tabular}{|c|c|c|c|}
\hline \multicolumn{4}{|c|}{ Período } \\
\hline $1940-1960$ & $1960-1980$ & $1980-2000$ & $2000-2019$ \\
\hline \multicolumn{4}{|c|}{ Número de documentos } \\
\hline 5 & 24 & 21 & 50 \\
\hline grammeme & SPC & $3 \mathrm{PM}$ & 1 \\
\hline hypergrammeme & -vte & kokama & matses \\
\hline uttereme & syntagm & evidential & $3 S G$ \\
\hline grammemes & tagmeme & clauses & $1 \mathrm{SG}$ \\
\hline hypermorpheme & $\mathrm{vb}$ & complement & ABS \\
\hline VCT & wa & chay & kakataibo \\
\hline VCI & NS & payne & clauses \\
\hline tbasevct & lexemic & owner & prox \\
\hline vbt & tho & speaker & KK \\
\hline asp & slot & adverbial & $1 \mathrm{PL}$ \\
\hline neg & clauses & BT & discourse \\
\hline tcorevbt & $\begin{array}{l}\text { predicative- } \\
\text { governed }\end{array}$ & prohibited & table \\
\hline alloclass & $-\mathrm{LU}$ & FUTURE & kaisa \\
\hline hyperclass & syntagms & $3 \mathrm{PF}$ & utsu \\
\hline hypergrammemes & $\mathrm{VH}$ & table & speaker \\
\hline GRAMMEMIC & sentence-base & adverbial & omagua \\
\hline vbl & vdth & chawra & ikian \\
\hline allogram & nominal-governed & BT & evidential \\
\hline hyper & TQ & pre-transition & SCQ \\
\hline vbi & verbal & PERFECT & markers \\
\hline
\end{tabular}

Es necesario señalar, sin embargo, que el uso de textos naturales y de una teoría tipológica contemporánea son cuestiones fundamentales para toda gramática y podrían enriquecer las aproximaciones descriptivas tempranas a las lenguas peruanas y elevar su potencial para estudios tipológicos innovadores. 
Figura 4. Distribución temporal de algunos términos de la tipología contemporánea en las gramáticas de lenguas peruanas

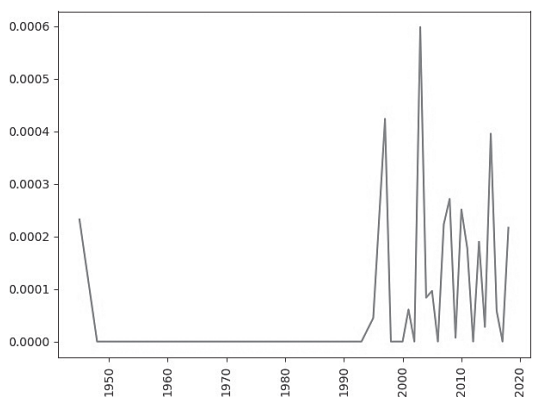

(a) Applicative (aplicativo)

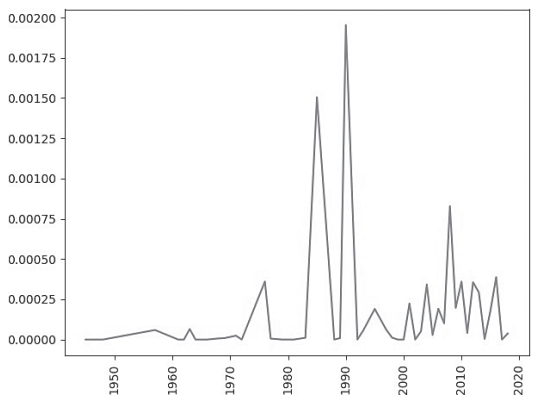

(c) Clitic (clítico)

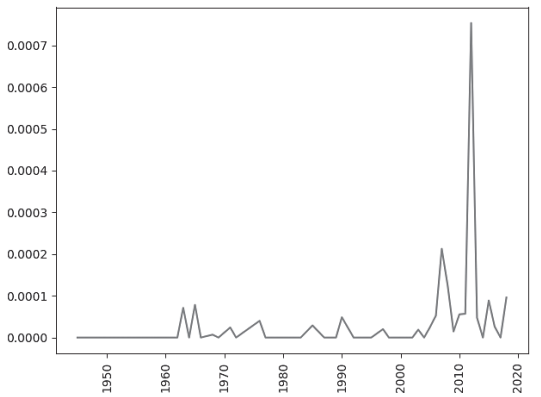

(e) Frustrative (frustrativo)

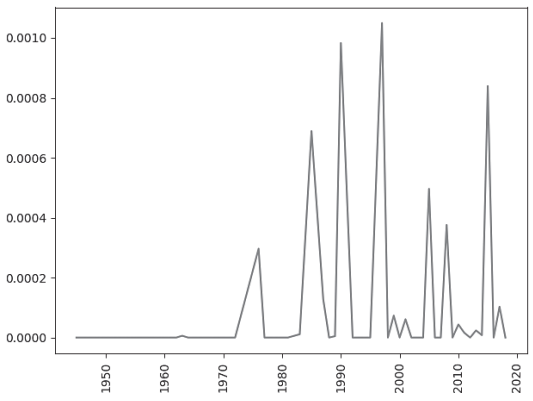

(b) Classifier (clasificador)

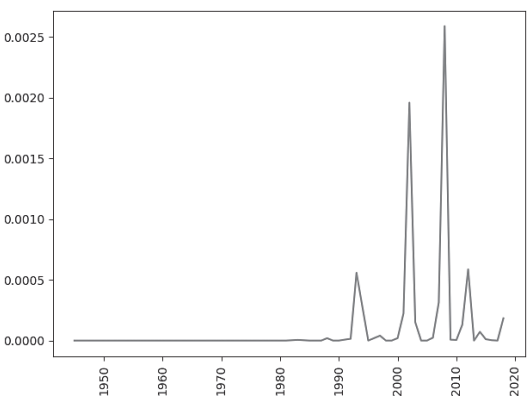

(d) Evidentiality (evidencialidad)

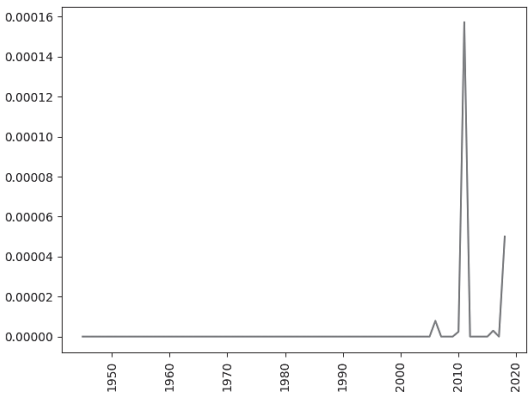

(f) Converb (co-verbo) 
Tabla 15. Gramáticas contemporáneas de lenguas peruanas

\begin{tabular}{|c|c|c|c|c|}
\hline Referencia & Lengua & Comprehensividad & $\begin{array}{l}\text { Base } \\
\text { empírica }\end{array}$ & Base teórica \\
\hline $\begin{array}{l}\text { Adelaar } \\
(1977)\end{array}$ & $\begin{array}{l}\text { quechua } \\
\text { de Tarma }\end{array}$ & $\begin{array}{l}43 \text { "secciones" con abun- } \\
\text { dantes textos y diccionario }\end{array}$ & $\begin{array}{l}\text { ejemplos } \\
\text { naturales y } \\
\text { elicitados }\end{array}$ & $\begin{array}{l}\text { tipológico- } \\
\text { funcional }\end{array}$ \\
\hline $\begin{array}{l}\text { Coler } \\
(2014)\end{array}$ & $\begin{array}{l}\text { aimara } \\
\text { muylaq }\end{array}$ & $\begin{array}{l}15 \text { capítulos con infor- } \\
\text { mación sobre partículas } \\
\text { discursivas y sobre contexto } \\
\text { sociolingüístico y con textos }\end{array}$ & $\begin{array}{l}\text { ejemplos } \\
\text { naturales y } \\
\text { elicitados }\end{array}$ & $\begin{array}{l}\text { tipológico- } \\
\text { funcional }\end{array}$ \\
\hline $\begin{array}{l}\text { Fleck } \\
(2003)\end{array}$ & matsés & $\begin{array}{l}12 \text { capítulos con discusión } \\
\text { sintáctica detallada y textos } \\
\text { ilustrativos }\end{array}$ & $\begin{array}{l}\text { ejemplos } \\
\text { naturales y } \\
\text { elicitados }\end{array}$ & $\begin{array}{l}\text { tipológico- } \\
\text { funcional }\end{array}$ \\
\hline $\begin{array}{l}\text { Mihas } \\
(2015)\end{array}$ & $\begin{array}{l}\text { ashéninka } \\
\text { del Alto } \\
\text { Perené }\end{array}$ & 10 capítulos + textos & $\begin{array}{l}\text { ejemplos } \\
\text { naturales y } \\
\text { elicitados }\end{array}$ & $\begin{array}{l}\text { tipológico- } \\
\text { funcional }\end{array}$ \\
\hline $\begin{array}{l}\text { Olawsky } \\
(2006)\end{array}$ & urarina & $\begin{array}{l}23 \text { capítulos con abundante } \\
\text { información dialectal y } \\
\text { sociolingüística + textos }\end{array}$ & $\begin{array}{l}\text { ejemplos } \\
\text { naturales y } \\
\text { elicitados } \\
\end{array}$ & $\begin{array}{l}\text { tipológico- } \\
\text { funcional }\end{array}$ \\
\hline $\begin{array}{l}\text { Overall } \\
(2017)\end{array}$ & awajún & $\begin{array}{l}18 \text { capítulos con textos } \\
\text { anotados y discusión sobre } \\
\text { estructuras discursivas }\end{array}$ & $\begin{array}{l}\text { ejemplos } \\
\text { naturales y } \\
\text { elicitados }\end{array}$ & $\begin{array}{l}\text { tipológico- } \\
\text { funcional }\end{array}$ \\
\hline $\begin{array}{l}\text { Payne } \\
(1985)\end{array}$ & yagua & $\begin{array}{l}7 \text { capítulos con detallada } \\
\text { descripción morfosintáctica, } \\
\text { pero solo un breve estudio } \\
\text { de fonología (incluye } \\
\text { textos) }\end{array}$ & $\begin{array}{l}\text { ejemplos } \\
\text { naturales y } \\
\text { elicitados }\end{array}$ & $\begin{array}{l}\text { tipológico- } \\
\text { funcional }\end{array}$ \\
\hline Peña (2015) & wampis & $\begin{array}{l}21 \text { capítulos con textos } \\
\text { anotados y discusión sobre } \\
\text { estructuras discursivas }\end{array}$ & $\begin{array}{l}\text { ejemplos } \\
\text { naturales y } \\
\text { elicitados }\end{array}$ & $\begin{array}{l}\text { tipológico- } \\
\text { funcional }\end{array}$ \\
\hline $\begin{array}{l}\text { Shimelman } \\
\text { (2017) }\end{array}$ & $\begin{array}{l}\text { quechua } \\
\text { de Yauyos }\end{array}$ & $\begin{array}{l}7 \text { capítulos, abundantes } \\
\text { ejemplos y textos glosados }\end{array}$ & $\begin{array}{l}\text { ejemplos } \\
\text { naturales y } \\
\text { elicitados }\end{array}$ & $\begin{array}{l}\text { tipológico- } \\
\text { funcional }\end{array}$ \\
\hline $\begin{array}{l}\text { Thiesen } \\
\text { y Weber } \\
(2012)\end{array}$ & bora & $\begin{array}{l}19 \text { capítulos, que incluye } \\
\text { discusión sobre discurso y } \\
\text { detallado análisis del sistema } \\
\text { tonal + textos glosados }\end{array}$ & $\begin{array}{l}\text { ejemplos } \\
\text { naturales y } \\
\text { elicitados }\end{array}$ & $\begin{array}{l}\text { tipológico- } \\
\text { funcional }\end{array}$ \\
\hline $\begin{array}{l}\text { Valenzuela } \\
(2003)\end{array}$ & $\begin{array}{l}\text { shipibo- } \\
\text { konibo }\end{array}$ & $\begin{array}{l}21 \text { capítulos con abundante } \\
\text { discusión de fenómenos de } \\
\text { transitividad + textos }\end{array}$ & $\begin{array}{l}\text { ejemplos } \\
\text { naturales y } \\
\text { elicitados }\end{array}$ & $\begin{array}{l}\text { tipológico- } \\
\text { funcional }\end{array}$ \\
\hline
\end{tabular}




\begin{tabular}{|c|c|c|c|c|}
\hline Referencia & Lengua & Comprehensividad & $\begin{array}{l}\text { Base } \\
\text { empírica }\end{array}$ & Base teórica \\
\hline $\begin{array}{l}\text { Weber } \\
(1996)\end{array}$ & $\begin{array}{l}\text { quechua } \\
\text { del } \\
\text { Huallaga }\end{array}$ & $\begin{array}{l}23 \text { capítulos con discusión } \\
\text { de estrategias discursivas e } \\
\text { interaccionales }\end{array}$ & $\begin{array}{l}\text { ejemplos } \\
\text { naturales y } \\
\text { elicitados }\end{array}$ & $\begin{array}{l}\text { tipológico- } \\
\text { funcional }\end{array}$ \\
\hline $\begin{array}{l}\text { Vallejos } \\
(2016)\end{array}$ & $\begin{array}{l}\text { kukama- } \\
\text { kukamiria }\end{array}$ & $\begin{array}{l}17 \text { capítulos con discusión } \\
\text { sobre discurso y textos } \\
\text { glosados }\end{array}$ & $\begin{array}{l}\text { ejemplos } \\
\text { naturales y } \\
\text { elicitados }\end{array}$ & $\begin{array}{l}\text { tipológico- } \\
\text { funcional }\end{array}$ \\
\hline $\begin{array}{l}\text { Zariquiey } \\
(2018)\end{array}$ & kakataibo & $\begin{array}{l}16 \text { capítulos que incluyen } \\
\text { secciones sobre discursivo } \\
\text { e interacción, contiene un } \\
\text { minidiccionario, una lista } \\
\text { de todos los morfemas } \\
\text { ligados de la lengua y textos } \\
\text { ilustrativos }\end{array}$ & $\begin{array}{l}\text { ejemplos } \\
\text { naturales y } \\
\text { elicitados }\end{array}$ & $\begin{array}{l}\text { tipológico- } \\
\text { funcional }\end{array}$ \\
\hline
\end{tabular}

Una gramática, entonces, debería ser comprehensiva, ser empíricamente sólida y tener una buena base teórica. Es difícil ofrecer una lista exhaustiva de las fuentes que cumplen con todas estas características. La Tabla 15 ofrece algunas de las gramáticas de lenguas peruanas que creemos se acercan a este ideal ordenadas alfabéticamente (la lista no es exhaustiva).

\section{El estado de la documentación de las lenguas peruanas}

Describir y documentar una lengua son tareas íntimamente relacionadas, pero teórica y metodológicamente distinguibles. Describir una lengua supone en buena cuenta insertarse en las tradiciones gramaticográfica y lexicográfica para producir objetos científicos como gramáticas y diccionarios. Ya hemos comentado largamente sobre la descripción de lenguas (particularmente de las gramáticas de lenguas peruanas) en este artículo. Con respecto a la documentación de una lengua, esta supone crear registros de alta calidad de una lengua, con la idea de depositarlos en un archivo especializado. En palabras de Himmelmann, "a language documentation is a lasting, multipurpose record of a language that aims to include as many and as varied records as practically feasible, covering all aspects of the 
set of interrelated phenomena commonly called a language" (2006: 1). Si bien la gramaticografía contemporánea requiere de registros como los propuestos en el marco del paradigma de la documentación de lenguas, el uso de estos archivos va más allá de la elaboración de gramáticas y la idea es que la documentación de lenguas debería estar al servicio también de otros proyectos entre los que la revitalización juega un rol central.

En este contexto, la pregunta sobre los avances en la documentación de lenguas peruanas resulta crucial. Para tratar de responder a esta pregunta, hemos emprendido una revisión de los archivos lingüísticos más importantes con la finalidad de valorar y cuantificar la existencia de colecciones sobre lenguas peruanas en dichos archivos. Además, hemos incluido en nuestro análisis los datos disponibles en el Archivo Digital de Lenguas Peruanas de la PUCP como ejemplo de un archivo alojado en el Perú y dedicado exclusivamente a las lenguas de nuestro país. Los archivos consultados para este estudio son listados a continuación (todos fueron consultados entre marzo y abril de 2019).

El Archivo Digital de Lenguas Peruanas (ADLP) se encuentra albergado en el Repositorio Institucional de la Pontificia Universidad Católica del Perú (PUCP) y es una iniciativa de su Departamento de Humanidades. Almacena registros de lenguas indígenas de diferentes regiones del Perú y, a la fecha, contiene colecciones audiovisuales de las familias pano, quechua, aimara, arawá, jíbaro y de la lengua de señas peruana, cuyos contenidos pueden descargarse de forma libre. Las lenguas peruanas representadas son un total de $19 .{ }^{25}$

El Endangered Languages Archive (ELAR) se encuentra alojado en el Repositorio Institucional de la Escuela de Estudios Orientales y Africanos (SOAS) de la Universidad de Londres. Preserva

\footnotetext{
25 Se incluye una colección de una variedad lingüística pano bajo la denominación xuxunawa que no es contabilizada en este número, ya que probablemente se trate de hablantes de un clan asociado a alguna otra lengua Pano del río Purús.
} 
colecciones multimedia de lenguas en peligro de extinción de todo el mundo con énfasis en África, Oriente Medio, Asia, Australia y América Latina. Su colección cuenta con grabaciones de usos cotidianos, arte verbal, canciones, narrativas, rituales y más, para más de 450 lenguas. Asimismo, almacena diccionarios, materiales pedagógicos como cartillas para la enseñanza de idiomas, transcripciones y traducciones de las grabaciones a los principales idiomas de contacto. En el caso de Perú, contiene más de 1000 registros pertenecientes a 9 lenguas indígenas.

El Archive of the Indigenous Languages of Latin America (AILLA) pertenece a la Universidad de Texas en Austin y reúne corpus lingüísticos de 52 países principalmente latinoamericanos, los cuales comprenden grabaciones, textos y otros materiales multimedia. Su colección cuenta, además, con materiales como gramáticas, diccionarios, etnografías y notas de campo. Las grabaciones abarcan un amplio rango de géneros: narrativas, cantos, oratorias, conversaciones, canciones, entre otros, muchas de las cuales se encuentran transcritas y traducidas al español. En relación con el Perú, contiene registros de 14 lenguas indígenas pertenecientes a las familias arawak, kawapana, pano, quechua y záparo, así como algunas lenguas aisladas. El acceso es gratuito mediante la creación de una cuenta.

The Language Archive (TLA) es una unidad del Instituto Max Planck para la Psicolingüística y comprende, a su vez, tres extensos archivos de datos lingüísticos. El primero de ellos es el archivo del proyecto Documentation of Endangered Languages (DOBES), que agrupa datos recopilados por investigadores de todo el mundo, muchos de los cuales están inscritos en el registro Memoria del Mundo de la UNESCO. Contiene datos de corpus de audio y video de lenguas de 54 países: fotografías, notas, datos experimentales y otra información relevante requerida para documentar y describir las lenguas y cómo las usan las personas. En el caso del Perú, contiene más de 2000 registros pertenecientes a 7 lenguas indígenas.

El segundo archivo de TLA proviene del proyecto Language Collections (LC), que reúne alrededor de 25 corpus lingüísticos, que en su totalidad comprenden un extenso conjunto de materiales 
audiovisuales en más de 350 lenguas de más de 65 países. En relación con el Perú, contiene registros audiovisuales de hablantes de quechua en Tarma, Huancayo, Huaral, Lamas, Ubinas y diversas localidades de la provincia de Yauyos y del departamento de Amazonas. Tales grabaciones fueron realizadas por investigadores entre 1967 y 2015.

Finalmente, el TLA incluye también al MPI-PL Archive, que agrupa datos recopilados por grupos de investigación en campos como la adquisición, comprensión y desarrollo del lenguaje; neurobiología y psicología del lenguaje; multilingüismo; así como las relaciones entre el lenguaje y la genética, y el lenguaje y la cognición, entre otros. Compila recursos en lenguas de más de 60 países y, en el caso específico del Perú, materiales audiovisuales en quechua del Cuzco y shawi.

EL Survey of California and Other Indian Languages (SCOIL) se encuentra adscrito al Departamento de Lingüística de la Universidad de California en Berkeley. Este archivo y centro de investigación tiene como misión documentar lenguas del continente americano. Su valiosa colección incluye, de manera notable, notas de campo y manuscritos de principios del siglo XX. A la fecha, contiene materiales primarios y secundarios de aproximadamente 130 lenguas, cincuenta de las cuales son nativas de la región de California y quince del Perú.

El total de lenguas peruanas representadas en los archivos lingüísticos consultados asciende a 45, aproximadamente el $50 \%$ de las 90 lenguas peruanas vivas consignadas en Glottolog (aunque desafortunadamente el cálculo no es exacto, ya que algunas de las lenguas para las que contamos registros en archivos no están contadas en Glottolog o viceversa). Si bien la cifra es considerable, es cierto al mismo tiempo que no contamos con ninguna documentación para prácticamente la mitad de las lenguas peruanas. En la Tabla 16, incluimos todos los casos de lenguas para las que no contamos con ninguna documentación para ninguno de sus dialectos. Nuevamente, no es posible hacer un paralelismo directo con Glottolog dado que las diferencias en la identificación y denomina- 
ción de lenguas peruanas no son triviales y no es posible establecer un paralelismo perfecto. El total de lenguas peruanas en la Tabla 16 asciende a 42 (contando al arazaire, ver nota al pie 3 ).

Tabla 16. Las lenguas peruanas no documentadas

\begin{tabular}{|c|c|c|}
\hline ISO 6393 & Lengua & Estado de vitalidad \\
\hline --- & arazaire & ¿extinta? \\
\hline hug & huachipaeri & casi extinta \\
\hline $\operatorname{ccc}$ & chamicuro & casi extinta \\
\hline myr & muniche & casi extinta \\
\hline inp & Iiapari & casi extinta \\
\hline arl & arabela & casi extinta \\
\hline qxt & quechua de Santa Ana de Tusi (Pasco) & moribunda \\
\hline qxa & quechua de Chiquián (Áncash) & moribunda \\
\hline qul & quechua del norte de Cajatambo & moribunda \\
\hline qxh & quechua de Panao (Huánuco) & moribunda \\
\hline kaq & kapanawa & moribunda \\
\hline qvs & quechua de San Martín & moribunda \\
\hline qur & quechua de Yanahuanca (Pasco) & en reemplazo \\
\hline not & nomatsiguenga & en reemplazo \\
\hline qve & quechua de Cajamarca & en reemplazo \\
\hline quf & quechua de Lambayeque & en reemplazo \\
\hline pis & yine & en reemplazo \\
\hline jqr & jaqaru & en reemplazo \\
\hline huv & wampis & en reemplazo \\
\hline $\mathrm{amr}$ & amarakaeri & en reemplazo \\
\hline ame & yanesha & en reemplazo \\
\hline- & lengua de señas de Inmaculada & amenazada \\
\hline cuj & mashco piro & amenazada \\
\hline qvm & quechua de Lauricocha & amenazada \\
\hline qvh & quechua de Huánuco & amenazada \\
\hline
\end{tabular}




\begin{tabular}{lll}
\hline ISO 6393 & Lengua & Estado de vitalidad \\
\hline qws & quechua de Áncash & amenazada \\
qvo & quechua de Napo & amenazada \\
qva & quechua de Ambo-Pasco & amenazada \\
apb & ashéninka Ucayali-Yurúa & amenazada \\
qxn & quechua del norte de Conchucos & amenazada \\
qwh & quechua de Áncash Huailas & amenazada \\
qwa & quechua de Corongo-Áncash & amenazada \\
qun & quechua del norte de Junín & amenazada \\
qub & quechua de Huallaga-Huánuco & amenazada \\
lsu & lengua de señas de Sina & amenazada \\
cpu & ashéninka del Pichís & amenazada \\
cpc & ajyíninka del Apurucayali & amenazada \\
qxp & quechua de Puno & no en peligro \\
spq & español de Loreto & no en peligro \\
qxu & quechua de La Unión (Arequipa) & no en peligro \\
qve & quechua del este de Apurímac & no en peligro \\
qup & quechua del sur de Pastaza & no en peligro \\
\hline
\end{tabular}

Estas son las lenguas peruanas para las que no contamos con ningún tipo de documentación en archivos lingüísticos especializados. La creación de bases de datos para estas lenguas es una tarea urgente y lo es todavía más para los casos de las cinco lenguas casi extintas (+ araizare) y las seis lenguas moribundas en la Tabla 16. Otras 45 lenguas o variedades de lengua peruanas vivas cuentan con una o más bases de datos en alguno de los archivos estudiados para este artículo. El estado de la documentación de estas lenguas se detalla a continuación en la Tabla 17. 
Tabla 17. Las lenguas peruanas en los archivos lingüísticos

\begin{tabular}{|c|c|c|c|c|c|}
\hline & Lengua & Familia & Archivo & $\begin{array}{l}\text { Datos } \\
\text { primarios }\end{array}$ & Descripción \\
\hline 1 & \multirow[t]{2}{*}{$\begin{array}{l}\text { aimara de } \\
\text { puno }\end{array}$} & \multirow[t]{2}{*}{ aimara } & ADLP & $\begin{array}{l}\text { grabaciones } \\
\text { de audio }\end{array}$ & $\begin{array}{l}\text { anotaciones, transcripciones, } \\
\text { glosas, cuestionario de } \\
\text { recojo de datos, información } \\
\text { sobre la lengua (inventario } \\
\text { fonológico) }\end{array}$ \\
\hline & & & SCOIL & $\begin{array}{l}\text { grabaciones de } \\
\text { audio, texto }\end{array}$ & $\begin{array}{l}\text { sesiones de elicitación, notas } \\
\text { de campo }\end{array}$ \\
\hline \multirow[t]{2}{*}{2} & \multirow[t]{2}{*}{ amahuaca } & \multirow[t]{2}{*}{ pano } & ADLP & $\begin{array}{l}\text { grabaciones } \\
\text { de audio }\end{array}$ & $\begin{array}{l}\text { transcripciones fonéticas, lista } \\
\text { léxica }\end{array}$ \\
\hline & & & AILLA & $\begin{array}{l}\text { grabaciones } \\
\text { de audio y } \\
\text { video, texto }\end{array}$ & no se pudo acceder a los datos \\
\hline 3 & asháninka & arawak & SCOIL & $\begin{array}{l}\text { grabaciones } \\
\text { de audio }\end{array}$ & $\begin{array}{l}\text { elicitaciones de palabras y } \\
\text { frases, datos etnográficos, } \\
\text { glosas, traducciones, } \\
\text { narraciones, canciones }\end{array}$ \\
\hline \multirow[t]{2}{*}{4} & \multirow[t]{2}{*}{$\begin{array}{l}\text { ashéninka } \\
\text { del Perené }\end{array}$} & \multirow[t]{2}{*}{ arawak } & AILLA & $\begin{array}{l}\text { grabaciones } \\
\text { de audio y } \\
\text { video }\end{array}$ & $\begin{array}{l}\text { transcripciones, narraciones, } \\
\text { cuentos }\end{array}$ \\
\hline & & & ELAR & $\begin{array}{l}\text { grabaciones } \\
\text { de audio y } \\
\text { video }\end{array}$ & $\begin{array}{l}\text { transcripciones, mitos, } \\
\text { cuentos populares, textos } \\
\text { etnográficos, oratoria, cantos, } \\
\text { trabalenguas y acertijos }\end{array}$ \\
\hline \multirow[t]{2}{*}{5} & \multirow[t]{2}{*}{ awajún } & \multirow[t]{2}{*}{ jíbaro } & ADLP & $\begin{array}{l}\text { grabaciones } \\
\text { de audio }\end{array}$ & $\begin{array}{l}\text { anotaciones, transcripciones, } \\
\text { glosas, cuestionario de recojo } \\
\text { de datos, información } \\
\text { sobre la lengua (inventario } \\
\text { fonológico) }\end{array}$ \\
\hline & & & SCOIL & $\begin{array}{l}\text { grabaciones } \\
\text { de audio }\end{array}$ & $\begin{array}{l}\text { narraciones, música, } \\
\text { conversaciones }\end{array}$ \\
\hline 6 & bora & bora & DOBES & $\begin{array}{l}\text { grabaciones } \\
\text { de audio y } \\
\text { video, texto }\end{array}$ & $\begin{array}{l}\text { transcripción, traducción, } \\
\text { costumbres, rituales, dis- } \\
\text { cursos, narraciones }\end{array}$ \\
\hline
\end{tabular}




\begin{tabular}{|c|c|c|c|c|c|}
\hline & Lengua & Familia & Archivo & $\begin{array}{l}\text { Datos } \\
\text { primarios }\end{array}$ & Descripción \\
\hline \multirow[t]{2}{*}{7} & \multirow[t]{2}{*}{ kakataibo } & \multirow[t]{2}{*}{ pano } & ELAR & $\begin{array}{l}\text { grabaciones, } \\
\text { texto }\end{array}$ & $\begin{array}{l}\text { transcripciones, análisis, } \\
\text { bosquejo gramatical y } \\
\text { vocabulario, narraciones, } \\
\text { conversaciones, canciones y } \\
\text { anuncios públicos }\end{array}$ \\
\hline & & & ADLP & $\begin{array}{l}\text { grabaciones } \\
\text { de audio } \\
\text { y video, } \\
\text { fotografías y } \\
\text { explicaciones } \\
\text { de plantas y } \\
\text { animales }\end{array}$ & $\begin{array}{l}\text { diccionario etnobiológico } \\
\text { trilingüe (kakataibo- } \\
\text { español-inglés), anotaciones, } \\
\text { traducciones, transcripciones, } \\
\text { glosas, cuentos y canciones } \\
\text { tradicionales }\end{array}$ \\
\hline \multirow[t]{2}{*}{8} & \multirow[t]{2}{*}{ cashinahua } & \multirow[t]{2}{*}{ pano } & ADLP & $\begin{array}{l}\text { grabaciones } \\
\text { de audio }\end{array}$ & $\begin{array}{l}\text { transcripciones fonéticas, lista } \\
\text { léxica }\end{array}$ \\
\hline & & & DOBES & $\begin{array}{l}\text { grabaciones } \\
\text { de audio y } \\
\text { video, texto }\end{array}$ & $\begin{array}{l}\text { transcripción, narraciones, } \\
\text { cantos, rutinas diarias, } \\
\text { conversaciones }\end{array}$ \\
\hline 9 & $\begin{array}{l}\text { chaninahua } \\
\text { (no en } \\
\text { Glottolog) }\end{array}$ & pano & ADLP & $\begin{array}{l}\text { grabaciones } \\
\text { de audio }\end{array}$ & $\begin{array}{l}\text { transcripciones fonéticas, lista } \\
\text { léxica }\end{array}$ \\
\hline \multirow[t]{2}{*}{10} & \multirow{2}{*}{$\begin{array}{l}\text { chankueshbo } \\
\text { (no en } \\
\text { Glottolog) }\end{array}$} & \multirow[t]{2}{*}{ pano } & ADLP & $\begin{array}{l}\text { grabaciones } \\
\text { de audio }\end{array}$ & narraciones, autobiografías \\
\hline & & & ELAR & $\begin{array}{l}\text { grabaciones } \\
\text { de audio }\end{array}$ & $\begin{array}{l}\text { estudio léxico, } \\
\text { transcripciones, anotaciones, } \\
\text { traducciones y análisis, } \\
\text { narraciones de historia oral y } \\
\text { otro género }\end{array}$ \\
\hline 11 & $\begin{array}{l}\text { witoto } \\
\text { (no en } \\
\text { Glottolog) }\end{array}$ & witoto & DOBES & $\begin{array}{l}\text { grabaciones } \\
\text { de audio y } \\
\text { video }\end{array}$ & $\begin{array}{l}\text { transcripción, traducción } \\
\text { rituales religiosos, cantos, } \\
\text { discursos }\end{array}$ \\
\hline 12 & $\begin{array}{l}\text { witoto } \\
\text { minica (no en } \\
\text { Glottolog) }\end{array}$ & witoto & DOBES & $\begin{array}{l}\text { grabaciones } \\
\text { de audio y } \\
\text { video, texto }\end{array}$ & $\begin{array}{l}\text { recolección, narraciones, } \\
\text { textos religiosos, discursos }\end{array}$ \\
\hline
\end{tabular}




\begin{tabular}{|c|c|c|c|c|c|}
\hline & Lengua & Familia & Archivo & $\begin{array}{l}\text { Datos } \\
\text { primarios }\end{array}$ & Descripción \\
\hline \multirow{3}{*}{\multicolumn{2}{|c|}{13 iquito }} & \multirow[t]{3}{*}{ záparo } & AILLA & $\begin{array}{l}\text { grabaciones } \\
\text { de audio y } \\
\text { video, texto }\end{array}$ & $\begin{array}{l}\text { traducciones, transcripciones, } \\
\text { comentarios, narraciones, } \\
\text { canciones, costumbres }\end{array}$ \\
\hline & & & ELAR & texto & $\begin{array}{l}\text { traducciones, diccionario } \\
\text { bilingüe (basado en el } \\
\text { conocimiento de los } \\
\text { consultores) }\end{array}$ \\
\hline & & & SCOIL & $\begin{array}{l}\text { grabaciones } \\
\text { de audio }\end{array}$ & $\begin{array}{l}\text { transcripciones, traducciones, } \\
\text { anotaciones, notas de campo, } \\
\text { materiales pedagógicos, } \\
\text { narraciones, opiniones, } \\
\text { diálogos, cantos }\end{array}$ \\
\hline \multirow[t]{2}{*}{14} & \multirow[t]{2}{*}{ iskonawa } & \multirow[t]{2}{*}{ pano } & ADLP & $\begin{array}{l}\text { grabaciones } \\
\text { de audio y } \\
\text { video }\end{array}$ & $\begin{array}{l}\text { anotaciones, narraciones, } \\
\text { conversaciones }\end{array}$ \\
\hline & & & AILLA & $\begin{array}{l}\text { grabaciones } \\
\text { de audio y } \\
\text { video, texto }\end{array}$ & $\begin{array}{l}\text { gramática, vocabulario } \\
\text { trilingüe, traducciones, } \\
\text { transcripciones, entrevistas, } \\
\text { canciones, cuentos, } \\
\text { testimonios }\end{array}$ \\
\hline \multirow[t]{2}{*}{16} & \multirow[t]{2}{*}{ kakinte } & \multirow[t]{2}{*}{ arawak } & ELAR & $\begin{array}{l}\text { grabaciones } \\
\text { de audio y } \\
\text { video, texto }\end{array}$ & $\begin{array}{l}\text { transcripciones, corpus FLEx, } \\
\text { elicitación léxica y gramatical } \\
\text { textos históricos, } \\
\text { autobiográficos y mitológicos, } \\
\text { entrevistas y conversaciones }\end{array}$ \\
\hline & & & SCOIL & $\begin{array}{l}\text { grabaciones } \\
\text { de audio, } \\
\text { texto }\end{array}$ & $\begin{array}{l}\text { sesiones de elicitación, notas } \\
\text { de campo, narraciones } \\
\text { tradicionales y autobiográficas }\end{array}$ \\
\hline \multirow[t]{2}{*}{17} & \multirow[t]{2}{*}{$\begin{array}{l}\text { kandozi- } \\
\text { shapra }\end{array}$} & \multirow[t]{2}{*}{$\begin{array}{l}\text { candoshi- } \\
\text { shapra }\end{array}$} & ELAR & $\begin{array}{l}\text { grabaciones } \\
\text { de audio y } \\
\text { video, texto }\end{array}$ & $\begin{array}{l}\text { transcripciones, traducciones } \\
\text { historia oral, narraciones } \\
\text { autobiográficas y textos de } \\
\text { procedimiento sobre temas de } \\
\text { artesanía }\end{array}$ \\
\hline & & & SCOIL & $\begin{array}{l}\text { grabaciones } \\
\text { de audio y } \\
\text { texto }\end{array}$ & $\begin{array}{l}\text { sesiones de elicitación sobre } \\
\text { el léxico, la gramática y la } \\
\text { historia, notas de campo }\end{array}$ \\
\hline
\end{tabular}




\begin{tabular}{|c|c|c|c|c|c|}
\hline & Lengua & Familia & Archivo & $\begin{array}{l}\text { Datos } \\
\text { primarios }\end{array}$ & Descripción \\
\hline 18 & $\begin{array}{l}\text { kukama- } \\
\text { kukamiria }\end{array}$ & tupí & ELAR & $\begin{array}{l}\text { grabaciones } \\
\text { de audio y } \\
\text { video, texto }\end{array}$ & $\begin{array}{l}\text { transcripciones, gramática } \\
\text { completa, diccionario } \\
\text { trilingüe, historias } \\
\text { tradicionales, historias de la } \\
\text { vida cotidiana, conversaciones } \\
\text { espontáneas, textos de } \\
\text { procedimientos y canciones }\end{array}$ \\
\hline \multirow[t]{2}{*}{19} & \multirow{2}{*}{$\begin{array}{l}\text { kulina del } \\
\text { río Curuçá } \\
\text { (no en } \\
\text { Glottolog) }\end{array}$} & \multirow[t]{2}{*}{ pano } & ADLP & $\begin{array}{l}\text { grabaciones } \\
\text { de audio }\end{array}$ & $\begin{array}{l}\text { vocabulario, narraciones, } \\
\text { autobiografías }\end{array}$ \\
\hline & & & ELAR & $\begin{array}{l}\text { grabaciones } \\
\text { de audio }\end{array}$ & $\begin{array}{l}\text { estudio léxico, transcripciones, } \\
\text { anotaciones, traducciones } \\
\text { y análisis, narraciones de } \\
\text { historia oral y otros géneros }\end{array}$ \\
\hline \multirow[t]{2}{*}{20} & \multirow[t]{2}{*}{$\begin{array}{l}\text { madija o } \\
\text { kulina }\end{array}$} & \multirow[t]{2}{*}{ arawá } & ADLP & $\begin{array}{l}\text { grabaciones } \\
\text { de audio }\end{array}$ & $\begin{array}{l}\text { transcripciones fonéticas, lista } \\
\text { léxica }\end{array}$ \\
\hline & & & AILLA & $\begin{array}{l}\text { grabaciones } \\
\text { de audio y } \\
\text { video, texto }\end{array}$ & \\
\hline 21 & maijuna & tucano & SCOIL & $\begin{array}{l}\text { grabaciones } \\
\text { de audio } \\
\text { y video, } \\
\text { fotografías, } \\
\text { texto }\end{array}$ & $\begin{array}{l}\text { transcripciones, traducciones, } \\
\text { anotaciones, notas de campo }\end{array}$ \\
\hline \multirow[t]{2}{*}{22} & \multirow[t]{2}{*}{ matsés } & \multirow[t]{2}{*}{ pano } & ADLP & $\begin{array}{l}\text { grabaciones } \\
\text { de audio }\end{array}$ & $\begin{array}{l}\text { diccionario, vocabulario, } \\
\text { narraciones, autobiografías }\end{array}$ \\
\hline & & & ELAR & $\begin{array}{l}\text { grabaciones } \\
\text { de audio }\end{array}$ & $\begin{array}{l}\text { estudio léxico, transcripciones, } \\
\text { anotaciones, traducciones y } \\
\text { análisis, narraciones de historia } \\
\text { oral y otros géneros }\end{array}$ \\
\hline \multirow[t]{2}{*}{23} & \multirow[t]{2}{*}{ matsigenka } & \multirow[t]{2}{*}{ arawak } & AILLA & $\begin{array}{l}\text { cuadernos de } \\
\text { texto }\end{array}$ & $\begin{array}{l}\text { traducciones, transcripciones } \\
\text { narraciones, costumbres, } \\
\text { relatos históricos }\end{array}$ \\
\hline & & & SCOIL & texto & $\begin{array}{l}\text { cuentos, mitos, leyendas, } \\
\text { tradiciones, costumbres, } \\
\text { creencias, anécdotas }\end{array}$ \\
\hline 24 & $\begin{array}{l}\text { nanti (no en } \\
\text { Glottolog) }\end{array}$ & arawak & AILLA & $\begin{array}{l}\text { grabaciones } \\
\text { de audio y } \\
\text { video, texto }\end{array}$ & $\begin{array}{l}\text { traducciones, transcripciones, } \\
\text { anotaciones, cantos } \\
\text { ceremoniales, poesía }\end{array}$ \\
\hline
\end{tabular}




\begin{tabular}{|c|c|c|c|c|c|}
\hline & Lengua & Familia & Archivo & $\begin{array}{l}\text { Datos } \\
\text { primarios }\end{array}$ & Descripción \\
\hline 25 & ocaina & witoto & DOBES & $\begin{array}{l}\text { grabaciones } \\
\text { de audio y } \\
\text { video, texto }\end{array}$ & $\begin{array}{l}\text { recolección, descripción } \\
\text { cantos, rituales, discursos, } \\
\text { textos religiosos }\end{array}$ \\
\hline 26 & omagua & tupí & SCOIL & $\begin{array}{l}\text { grabaciones } \\
\text { de audio, } \\
\text { texto }\end{array}$ & $\begin{array}{l}\text { notas de campo, descripción } \\
\text { gramatical preliminar, } \\
\text { bosquejo fonológico, } \\
\text { diccionario, traducciones, } \\
\text { base de datos léxica (FLEx), } \\
\text { narraciones, sesiones elicitadas }\end{array}$ \\
\hline 27 & $\begin{array}{l}\text { quechua de } \\
\text { Ayacucho }\end{array}$ & quechua & SCOIL & $\begin{array}{l}\text { grabaciones } \\
\text { de audio }\end{array}$ & $\begin{array}{l}\text { recitaciones de palabras y } \\
\text { frases }\end{array}$ \\
\hline \multirow[t]{2}{*}{28} & \multirow[t]{2}{*}{$\begin{array}{l}\text { quechua de } \\
\text { Chachapoyas }\end{array}$} & \multirow[t]{2}{*}{ quechua } & AILLA & $\begin{array}{l}\text { grabaciones } \\
\text { de audio, } \\
\text { fotografías y } \\
\text { texto }\end{array}$ & $\begin{array}{l}\text { transcripciones, listado de } \\
\text { términos }\end{array}$ \\
\hline & & & $\mathrm{LC}$ & $\begin{array}{l}\text { grabaciones } \\
\text { de audio y } \\
\text { video }\end{array}$ & discursos, canciones \\
\hline \multirow[t]{3}{*}{29} & \multirow[t]{3}{*}{$\begin{array}{l}\text { quechua de } \\
\text { Cuzco }\end{array}$} & \multirow[t]{3}{*}{ quechua } & AILLA & $\begin{array}{l}\text { grabaciones } \\
\text { de audio y } \\
\text { video, texto }\end{array}$ & $\begin{array}{l}\text { descripción fonológica, } \\
\text { vocabulario, transcripciones, } \\
\text { traducciones, leyenda de glosas } \\
\text { trilingüe, narraciones, dibujos }\end{array}$ \\
\hline & & & LC & texto & transcripciones, discursos \\
\hline & & & MPI-PL & $\begin{array}{l}\text { grabaciones } \\
\text { de audio y } \\
\text { video }\end{array}$ & narraciones, diálogos \\
\hline 30 & $\begin{array}{l}\text { quechua de } \\
\text { Jauja }\end{array}$ & quechua & $\mathrm{LC}$ & $\begin{array}{l}\text { grabaciones } \\
\text { de audio y } \\
\text { texto }\end{array}$ & $\begin{array}{l}\text { discursos, diálogos, } \\
\text { narraciones, canciones }\end{array}$ \\
\hline 31 & $\begin{array}{l}\text { quechua de } \\
\text { Pacaraos }\end{array}$ & quechua & LC & $\begin{array}{l}\text { grabaciones } \\
\text { de audio }\end{array}$ & \\
\hline 32 & $\begin{array}{l}\text { quechua } \\
\text { de Ubinas } \\
\text { (no en } \\
\text { Glottolog) }\end{array}$ & quechua & LC & $\begin{array}{l}\text { grabaciones } \\
\text { de audio }\end{array}$ & diálogos \\
\hline
\end{tabular}




\begin{tabular}{|c|c|c|c|c|c|}
\hline & Lengua & Familia & Archivo & $\begin{array}{l}\text { Datos } \\
\text { primarios }\end{array}$ & Descripción \\
\hline \multirow[t]{4}{*}{33} & \multirow[t]{4}{*}{$\begin{array}{l}\text { quechua de } \\
\text { Yauyos }\end{array}$} & \multirow[t]{4}{*}{ quechua } & ADLP & $\begin{array}{l}\text { grabaciones } \\
\text { de audio y } \\
\text { video, texto }\end{array}$ & $\begin{array}{l}\text { bosquejo gramatical, léxico, } \\
\text { transcripciones, glosas, tra- } \\
\text { ducciones al español e inglés, } \\
\text { anotaciones, narraciones }\end{array}$ \\
\hline & & & AILLA & $\begin{array}{l}\text { grabaciones } \\
\text { de audio y } \\
\text { video, texto }\end{array}$ & $\begin{array}{l}\text { gramática, narraciones, } \\
\text { entrevistas, costumbres }\end{array}$ \\
\hline & & & $\mathrm{LC}$ & $\begin{array}{l}\text { grabaciones } \\
\text { de audio y } \\
\text { video }\end{array}$ & $\begin{array}{l}\text { bosquejo gramatical, léxico, } \\
\text { glosas, traducciones, anota- } \\
\text { ciones, catálogo de plantas } \\
\text { medicinales, cuentos y can- } \\
\text { ciones tradicionales, discursos }\end{array}$ \\
\hline & & & SCOIL & $\begin{array}{l}\text { grabaciones } \\
\text { de audio, } \\
\text { fotografías y } \\
\text { texto }\end{array}$ & $\begin{array}{l}\text { sesiones de elicitación, } \\
\text { léxico, gramática, diario de } \\
\text { campo, cuentos tradicionales, } \\
\text { canciones, conversaciones }\end{array}$ \\
\hline 34 & resígaro & arawak & DOBES & $\begin{array}{l}\text { grabaciones } \\
\text { de audio y } \\
\text { video, texto }\end{array}$ & $\begin{array}{l}\text { recolección, discurso, cantos, } \\
\text { conversaciones }\end{array}$ \\
\hline \multirow[t]{2}{*}{35} & \multirow{2}{*}{$\begin{array}{l}\text { sharanawa } \\
\text { (no en } \\
\text { Glottolog) }\end{array}$} & \multirow[t]{2}{*}{ pano } & ADLP & $\begin{array}{l}\text { grabaciones } \\
\text { de audio }\end{array}$ & $\begin{array}{l}\text { transcripciones fonéticas, lista } \\
\text { léxica }\end{array}$ \\
\hline & & & AILLA & $\begin{array}{l}\text { grabaciones } \\
\text { de audio y } \\
\text { video, texto }\end{array}$ & $\begin{array}{l}\text { mitos, canciones ceremoniales: } \\
\text { shamanísticas, de curación, } \\
\text { ayahuasca }\end{array}$ \\
\hline \multirow[t]{2}{*}{36} & \multirow[t]{2}{*}{ shawi } & \multirow[t]{2}{*}{ cahuapana } & AILLA & $\begin{array}{l}\text { grabaciones } \\
\text { de audio y } \\
\text { video, texto }\end{array}$ & transcripciones, entrevistas \\
\hline & & & MPI-PL & $\begin{array}{l}\text { grabaciones } \\
\text { de audio y } \\
\text { video }\end{array}$ & $\begin{array}{l}\text { anotaciones, narraciones, } \\
\text { diálogos }\end{array}$ \\
\hline 37 & $\begin{array}{l}\text { shipibo- } \\
\text { konibo }\end{array}$ & pano & ADLP & $\begin{array}{l}\text { grabaciones } \\
\text { de audio }\end{array}$ & anotaciones, lista léxica \\
\hline 38 & shiwilu & cahuapana & AILLA & $\begin{array}{l}\text { grabaciones } \\
\text { de audio y } \\
\text { video, texto }\end{array}$ & $\begin{array}{l}\text { traducciones, diccionario } \\
\text { trilingüe, entrevistas, } \\
\text { actividades de trabajo de } \\
\text { campo, narraciones, canciones }\end{array}$ \\
\hline 39 & taushiro & $\begin{array}{l}\text { lengua } \\
\text { aislada }\end{array}$ & SCOIL & $\begin{array}{l}\text { grabaciones } \\
\text { de audio, } \\
\text { texto }\end{array}$ & $\begin{array}{l}\text { sesiones de elicitación de léxico, } \\
\text { gramática e historia; textos / } \\
\text { notas de campo, materiales } \\
\text { previamente publicados }\end{array}$ \\
\hline
\end{tabular}




\begin{tabular}{|c|c|c|c|c|c|}
\hline & Lengua & Familia & Archivo & $\begin{array}{l}\text { Datos } \\
\text { primarios }\end{array}$ & Descripción \\
\hline & \multirow[t]{2}{*}{ tikuna } & \multirow[t]{2}{*}{$\begin{array}{l}\text { lengua } \\
\text { aislada }\end{array}$} & AILLA & $\begin{array}{l}\text { grabaciones } \\
\text { de audio y } \\
\text { video, textos }\end{array}$ & discursos espontáneos \\
\hline & & & SCOIL & $\begin{array}{l}\text { grabaciones } \\
\text { de audio, } \\
\text { imágenes y } \\
\text { texto }\end{array}$ & $\begin{array}{l}\text { transcripciones, traducciones } \\
\text { y análisis de ticuna / } \\
\text { conversaciones y discursos } \\
\text { naturales, cuadernos de campo }\end{array}$ \\
\hline \multirow[t]{2}{*}{41} & \multirow[t]{2}{*}{ urarina } & \multirow[t]{2}{*}{$\begin{array}{l}\text { lengua } \\
\text { aislada }\end{array}$} & ELAR & $\begin{array}{l}\text { grabaciones } \\
\text { de audio } \\
\text { y video, } \\
\text { grabaciones } \\
\text { de música }\end{array}$ & $\begin{array}{l}\text { materiales de alfabetización } \\
\text { (cuentos bilingües), listas de } \\
\text { palabras, secuencias de video, } \\
\text { narraciones, conversaciones y } \\
\text { descripciones de imágenes }\end{array}$ \\
\hline & & & SCOIL & $\begin{array}{l}\text { grabaciones } \\
\text { de audio, } \\
\text { fotografías e } \\
\text { imágenes }\end{array}$ & $\begin{array}{l}\text { canciones, entrevistas y } \\
\text { sesiones de elicitación sobre la } \\
\text { lengua omurana y la historia } \\
\text { regional de la cuenca del río } \\
\text { Urituyacu / notas de campo }\end{array}$ \\
\hline 42 & yagua & $\begin{array}{l}\text { peba } \\
\text { yagua }\end{array}$ & DOBES & $\begin{array}{l}\text { grabaciones } \\
\text { de audio y } \\
\text { video }\end{array}$ & $\begin{array}{l}\text { recolección } \\
\text { bailes tradicionales }\end{array}$ \\
\hline \multirow[t]{3}{*}{43} & \multirow{3}{*}{$\begin{array}{l}\text { yaminawa } \\
\text { (no en } \\
\text { Glottolog) }\end{array}$} & \multirow[t]{3}{*}{ pano } & ADLP & $\begin{array}{l}\text { grabaciones } \\
\text { de audio }\end{array}$ & $\begin{array}{l}\text { transcripciones fonéticas, lista } \\
\text { léxica }\end{array}$ \\
\hline & & & AILLA & $\begin{array}{l}\text { grabaciones } \\
\text { de audio y } \\
\text { video, texto }\end{array}$ & mitos \\
\hline & & & SCOIL & $\begin{array}{l}\text { grabaciones } \\
\text { de audio }\end{array}$ & $\begin{array}{l}\text { cuentos tradicionales, } \\
\text { narraciones cosmológicas y } \\
\text { cuentos de animales }\end{array}$ \\
\hline \multirow[t]{3}{*}{44} & \multirow[t]{3}{*}{ yora o nawa } & \multirow[t]{3}{*}{ pano } & ADLP & $\begin{array}{l}\text { grabaciones } \\
\text { de audio }\end{array}$ & $\begin{array}{l}\text { transcripciones fonéticas, lista } \\
\text { léxica }\end{array}$ \\
\hline & & & ELAR & $\begin{array}{l}\text { grabaciones } \\
\text { de audio y } \\
\text { video, texto }\end{array}$ & $\begin{array}{l}\text { transcripciones, traducciones } \\
\text { mitos e historias orales, } \\
\text { sanaciones y canciones }\end{array}$ \\
\hline & & & SCOIL & $\begin{array}{l}\text { grabaciones } \\
\text { de audio }\end{array}$ & $\begin{array}{l}\text { cuentos tradicionales, } \\
\text { narraciones cosmológicas y } \\
\text { cuentos de animales }\end{array}$ \\
\hline 45 & $\begin{array}{l}\text { lengua de } \\
\text { señas peruana }\end{array}$ & & ADLP & $\begin{array}{l}\text { grabaciones } \\
\text { de video }\end{array}$ & $\begin{array}{l}\text { descripción general de cada } \\
\text { sesión de video }\end{array}$ \\
\hline
\end{tabular}


Si asumimos que una documentación lingüística contemporánea supone emplear los medios más modernos para la tarea de compilar datos lingüísticos, podríamos establecer como un estándar mínimo de buena documentación a aquellas bases de datos que incluyan audio, video y transcripción de narraciones y conversaciones naturales. Aunque no es posible valorar la calidad de las bases de datos disponibles en el marco de este estudio, es claro que solo 25 lenguas peruanas (o 26 si contamos los dos dialectos de witoto por separado) cuentan con bases de datos que satisfagan este requisito. La documentación moderna de las otras 20 lenguas es también una tarea urgente. Sin embargo, la definición misma de documentación lingüística supone que no existe la documentación completa. Por ello, incluso aquellas lenguas que tengan ya una documentación moderna deberían seguir siendo documentadas, idealmente en proyectos colaborativos en los que los miembros de las comunidades de habla y sus necesidades sean considerados como centrales. Sin embargo, los datos presentados y sistematizados aquí nos ayudan a trazar prioridades y empezar a pensar en un plan a largo plazo.

\section{6. ¿Y la revitalización?: conclusiones y recomendaciones a futuro}

El presente artículo ha ofrecido un estado del arte de la descripción y documentación de las lenguas peruanas. Si bien, con relación a la primera, es bastante lo que se ha avanzado, nuestro estudio sostiene categóricamente que la tarea de describir comprehensivamente las lenguas peruanas requiere todavía de una atención urgente en tanto que incluso muchas de las lenguas que cuentan con gramáticas requieren de estudios más modernos y comprehensivos. Describir aquellas lenguas que no cuentan con una gramática es todavía una tarea más urgente, que requiere de nuestra atención inmediata.

También es larga la deuda en materia de documentación y creación de archivos lingüísticos completos. Solo alrededor del 50 $\%$ de nuestras lenguas cuentan con algún material depositado en algún archivo y el número decrece significativamente cuando nos 
enfocamos en aquellos casos para los que contamos con documentación rigurosa. Incluso, lenguas para las que contamos con gramáticas comprehensivas no cuentan con bases de datos lingüísticas completas. Es menester que los lingüistas que hayamos trabajado con lenguas peruanas pongamos nuestros materiales a disposición de las comunidades a través de archivos digitales, respetando desde luego todos los requerimientos éticos que esta tarea implica. En esa tarea, archivos locales como el Archivo Digital de Lenguas Peruanas de la PUCP son cruciales, ya que es vital que los materiales sobre la diversidad lingüística peruana se archiven en instituciones nacionales. La participación del Estado peruano, a través de la Dirección de Lenguas Indígenas, en la recopilación de estos materiales es fundamental. Es importante también que los pueblos indígenas tengan espacios para tomar decisiones y participar activamente en este proceso.

Algo que debe llamar la atención de las personas comprometidas con la diversidad lingüística peruana es el poco apoyo estatal con el que contamos para su documentación y estudio. Es alarmante que prácticamente la totalidad de proyectos que han dado lugar a los archivos digitales y gramáticas comprehensivas de lenguas peruanas hayan sido financiados con fondos extranjeros (Pilar Valenzuela, comunicación personal). Eso debería invitarnos a emprender lo antes posible el proceso de creación de una política nacional para la investigación en lenguas indígenas peruanas, en la que este y otros aspectos se sometan a reglamentación. En este proceso, nuevamente, la participación de las organizaciones indígenas es imperativa.

Dentro de una política de este tipo, un aspecto crucial es el de la revitalización y promoción de lenguas peruanas. Es menester que las tareas de documentar, describir y revitalizar nuestras lenguas se entiendan como una trilogía indesligable. Integrar dichas tareas debería ser un compromiso de todos los investigadores que trabajen con comunidades de habla en el Perú y, particularmente, con pueblos indígenas. Todo proyecto de investigación con cualquier lengua peruana debería tener un componente de revitalización y 
trabajo colaborativo con la comunidad. De otra forma, no debería recibir licencia social para llevarse a cabo. Es vital que el Estado peruano promueva esta iniciativa y que se empiece a poner un énfasis en la necesidad de que los proyectos de investigación tengan un impacto positivo en la vida lingüística de nuestros pueblos. De la mano de dicho proceso, debería emprenderse un registro de investigadores para saber qué proyectos se están llevando a cabo y con qué lenguas. Dicho registro debería ser transparente en términos de los objetivos, los métodos, los presupuestos y los esfuerzos por incorporar a las comunidades de habla. Estado, academia y organizaciones sociales (e indígenas, particularmente) deberían trabajar colaborativamente para promover una verdadera política de investigación en lenguas peruanas que atienda los requerimientos de los distintos actores involucrados. En esa línea, esta modesta contribución puede tomarse como referencia para que podamos definir prioridades como sociedad y para que Estado, academia y organizaciones indígenas trabajen juntos en una misma dirección.

\section{Referencias bibliográficas}

AdelaAr, Willem

1977 Tarma Quechua: Grammar, texts and dictionary. Tesis doctoral. Ámsterdam: Universiteit van Amsterdam.

Alexander-Bakkerus, Astrid

2005 Eighteenth-Century Cholón. Tesis doctoral. Leiden: Rijksuniversiteit Leiden.

Aluin, Trevor R.

1976 A Grammar of Resígaro. Vol. 1-3. Horsleys Green: Summer Institute of Linguistics.

Alviano, Frei Fidelis de

1944 "Gramática, Dicionário, Verbos e Frases e Vocabulario Prático da Língua dos Índios Ticunas”. Revista do Instituto Geográfico da Babia. CLXXX, 3-194. 
ANDERson, Doris G.

1962 Conversational Ticuna. Yarinacocha: Instituto Lingüístico de Verano.

1980 Ticuna Conversacional: Lecciones para el aprendizaje del Idioma. Lima: Instituto Lingüístico de Verano.

Bendor-SAmuel, John T.

1979 The structure and function of the verbal piece in the Jebero language. Lima: Instituto Lingüístico de Verano.

BERTONIO, Ludovico

1603 Arte y gramatica muy copiosa de la lengua aymara. Roma: Luis Zanetti.

Black, Nancy, Verena Bolli y Eusebio Ticsi Z.

1990 Lecciones para el aprendizaje del quechua del sureste de Pasco y el norte de Junín. Lima: Dirección Departamental de Educación-Pasco / Instituto Lingüístico de Verano.

Brenzinger, Matthias, Arienne M. Dwyer, Tjeerd De Graaf, Colette Grinevald, Michael Krauss, Osahito Miyaoka, Nicholas Ostler ... Ofelia ZEPEDA

2003 Language vitality and endangerment. París: International Expert Meeting on UNESCO Programme Safeguarding of Endangered Languages.

Calvo Pérez, Julio

1993 Pragmática y gramática del quechua cuzqueño. Cuzco: Centro de Estudios Regionales Andinos Bartolomé de Las Casas.

Camargo, Eliane

1991 Phonologie, morphologie et syntaxe: étude descriptive de la langue Caxinaua (Pano). Tesis doctoral. París: Université de la Sorbonne (Paris IV).

Campbell, Lyle

2017 About the catalogue of the endangered languages. Consultado: $\mathrm{s} / \mathrm{f}<\mathrm{http}: / /$ endangeredlanguages.com/about/ $>$.

Cerrón-Palomino, Rodolfo

1976 Gramática quechua: Junín-Huanca. Lima: Ministerio de Educación / Instituto de Estudios Peruanos.

1987 Lingüística quechua. Cuzco: Centro de Estudios Regionales Andinos Bartolomé de las Casas. 
Clark, Brenda

2017 A grammatical sketch of Sivia Sign Language. Tesis doctoral. Manoa: University of Hawaii at Manoa.

Coler, Matt

2010 A grammatical description of Muylaq' Aymara. Tesis doctoral. Ámsterdam: Vrije Universiteit Amsterdam.

2014 A Grammar of Muylaq' Aymara: Aymara as spoken in Southern Peru. Leiden: Brill.

Corbera Mori, Angel Humberto

1994 Fonologia e gramática do Aguaruna (Jívaro). Tesis doctoral. Campinas: Universidade Estadual de Campinas.

Crevels, Mily

2012 "Language endangerment in South America: The clock is ticking”. En The Indigenous Languages of South America: A Comprehensive Guide. Eds., Lyle Campbell y Verónica Grondona. Berlín: Mouton, 167-233.

CunHA, Carla Maria

1993 A Morfossintaxe da Lingua Arara (Pano) do Acre. Tesis de maestría. Recife: Universidade Federal de Pernambuco.

Cusinuamán, Antonio

1976 Gramática quechua: Cuzco-Collao. Lima: Ministerio de Educación / Instituto de Estudios Peruanos.

Dedenbach-Salazar Sáenz, Sabine

1993 Una Gramática Colonial del Quichua del Ecuador: Transcripción e Interpretación de un manuscrito del Archivo Histórico Nacional de Colombia. Bonn: Institute of Amerindian Studies, University of St. Andrews / Bonner Amerikanistische Studien.

Deza Galindo, Juan Francisco

1992 Gramática de la Lengua Aymara. Lima: Artex Editores.

DiENST, Stefan

2006 A Reference Grammar of Kulina. Tesis doctoral. Melbourne: LaTrobe University.

2014 A Grammar of Kulina. Berlín: De Gruyter Mouton. 
DuFf-Tripp, Martha

1997 Gramática del idioma yanesha' (amuesha). Lima: Ministerio de Educación / Instituto Lingüístico de Verano.

EAKIN, Lucille

1991 Lecciones para el aprendizaje del idioma yaminabua. Lima: Ministerio de Educación / Instituto Lingüístico de Verano.

Escribens, Augusto y Paul Proulx

1970 Gramática del quechua de Huaylas. Lima: Universidad Nacional Mayor de San Marcos.

Ethnologue

s/f Ethnologue. Languages of the world. Consultado: s/f. <https://www.ethnologue.com/>.

Fagua Rincón, Doris Patricia

2013 Aspects morphosyntaxiques de l'ocaina: autour des classes lexicales. Tesis doctoral. París: Université de Paris / Dénis Diderot.

FAUst, Norma

1972 Gramática Cocama: Lecciones para el aprendizaje del idioma cocama. Yarinacocha: Instituto Lingüístico de Verano.

1973 Lecciones para el aprendizaje del idioma shipibo-conibo. Yarinacocha: Instituto Lingüístico de Verano.

1978 Gramática cocama: lecciones para el aprendizaje del idioma cocama. Lima: Instituto Lingüístico de Verano.

FAust, Norma y Eugene E. Loos

2002 Gramática del Idioma Yaminabua. Lima: Instituto Lingüístico de Verano.

FERNÁNDEZ NodAL, José

1872 Elementos de gramática Quichua ó idioma de los Yncas. Cuzco: Agencia del Autor.

FleCK, David W.

2003 A Grammar of Matses. Tesis doctoral. Houston: Rice University. 
GonzÁlez Holguín, Diego

[1607] $1842 \quad$ Gramática y arte nueva de la lengua general de todo el Peru: llamada lengua qquichua o lengua del inca. Pagano.

Grajeda Challco, Braulio y Asis Orlando Vela Flores

1976 Gramática quechua: enciclopedia de gramática quechua integral. Lima: Ediciones Instituto Superior de Quechua del Perú.

Grondin Nadon, Marcelo

[1985] 1999 Método de Aymara. La Paz: Los Amigos del Libro.

Guardia Mayorga, César A.

1973 Gramática Kechwa: runasimi allin rimay yachay. Lima: Los Andes.

Hammarström, Harald, Thom Castermans, Robert Forkel, Kevin

Verbeek, Michel A. Westenberg y Bettina Speckmann

2018 "Simultaneous visualization of language endangerment and language description". Language Documentation E Conservation. 12, 359-392.

HAMmarström, Harald, Robert Forkel y Martin Haspelmath

2018 Glottolog 3.3. Jena: Max Planck Institute for the Science of Human History. Consultado: marzo de 2019. < https:// glottolog.org/>.

Hanson, Rebecca

2010 A grammar of Yine (Piro). Tesis doctoral. Melbourne: LaTrobe University.

HaRdman, Martha J.

1966 Jaqaru: Outline of Phonological and Morphological Structure. Berlín: Mouton de Gruyter.

1978 "Jaqi: The Linguistic Family". International Journal of American Linguistics. 44, 2, 146-153.

1983 Jaqaru: Compendio de Estructura Fonológica y Morfológica. Lima: Instituto Indigenista Interamericano / Instituto de Estudios Peruanos.

2000 Jaqaru: Compendio de Estructura Fonológica y Morfológica. Múnich: Lincom.

2001 Aymara. Múnich: Lincom. 
Hardman, Martha J., Juan VÁsquez y Juan de Dios Yapita

2001 Aymara: Compendio de Estructura Fonológica Grammatical. La Paz: Instituto de Lengua y Cultura Aymara.

Helberg Chávez, Heinrich Albert

1984 Skizze einer Grammatik des Amarakaeri. Tesis doctoral. Tubinga: Eberhard-Karls-Universität.

Himmelmann, Nikolaus

2006 "Language documentation: What is it and what is it good for?"

En Essentials of language documentation. Eds., Jost Gippert, Nikolaus P. Himmelmann y Ulrike Mosel. Berlín: Mouton de Gruyter, 1-30.

Hintz, Daniel J. y D. Marlene Ballena

2000 Características distintivas del Quechua de Corongo: perspectivas histórica y sincrónica. Lima: Instituto Lingüístico de Verano.

Hoggarth, Leslie

2004 Contributions to Cuzco Quechua grammar. Aachen: Shaker.

Howkins, Angela Margaret

1977 Syntactic relations in San Martín Quechua. Tesis doctoral. St. Andrews: University of St. Andrews.

Huayhua Pari, Felipe

2001 Gramática descriptiva de la lengua Aimara. Lima: Negocios Arco Iris SRL.

Instituo Max Planck

s/f The Language Archive (TLA). Consultado: marzo-abril de 2019. <https://tla.mpi.nl/>

ITIER, César

1997 Parlons Quechua: La langue du Cuzco. París: L'Harmattan.

Johnson, Orville E. y Stephen E. Levinsohn

1990 Gramática Secoya. Quito: Instituto Lingüístico de Verano.

Kaxinawé, Joaquim Paulo de Lima

2014 Uma gramática da língua Hãtxa Kuin. Tesis doctoral. Brasilia:

Universidade de Brasília. 
LAI, I-Wen

2009 Time in the Iquito Language. Tesis doctoral. Austin: University of Texas at Austin.

Lee, Nala H. y John R. VAn WAy

2018 "The language endangerment index". En Cataloguing the world's endangered languages. Eds., Lyle Campbell y Anna Belew. Londres: Routledge, 66-78.

Lewis, Paul M. y Gary F. Simons

2010 "Assessing endangerment: Expanding Fishman's Gids". Revue Roumaine de Linguistique. 55, 2, 103-120.

LYON, Patricia J.

1975 "Dislocación tribal y clasificaciones lingüísticas en la zona del río Madre de Dios”. En Lingüística e Indigenismo Moderno de América (Trabajos presentados al XXXIX Congreso Internacional de Americanistas). Vol. 5. Eds., Rosalía Avales de Matos y Rogger Ravines. Lima: Instituto de Estudios Peruanos, 185207.

Manning, Christopher D., Prabhakar Raghavan y Hinrich Schütze

2008 Introduction to Information Retrieval. Cambridge: Cambridge University Press.

Mata, Pedro de la

2007 [1748] Arte de la lengua Cholona. Vervuert: Iberoamericana.

MatTeson, Esther

1963 The Piro (Arawak) language. Tesis doctoral. Berkeley: University of California at Berkeley.

1965 The Piro (Arawakan) Language. Berkeley: University of California Press.

Michael, Lev David

2008 Nanti evidential practice: Language, knowledge, and social action in an Amazonian society. Tesis doctoral. Austin: University of Texas at Austin.

MidDENDORF, Ernest W.

1890 Das Runa Simi oder die Keshua-Sprache wie sie gegenwärtig in der Provinz von Cusco gesprochen wird. Vol. 1. Die einheimischen Sprachen Perus. Leipzig: F. A. Brockhaus. 
1892 Das Muchik oder die Chimu-Sprache mit einer einleitung über die culturvölker, die gleichzeitig mit den Inkas und Aimaraàs in Südamerika lebten und einem Anbang über die ChibchaSprache. Die einheimischen Sprachen Perus. Leipzig: F. A. Brockhaus.

1970 Gramática Keshua. Trad., Ernesto More. Madrid: Aguilar.

Minas, Elena

2010 Essentials of Ashéninka Perené grammar. Tesis doctoral. Milwaukee: University of Wisconsin-Milwaukee.

2015 A Grammar of Alto Perené (Arawak). Berlín: Mouton de Gruyter.

Ministerio de Educación del Perú

2013 Documento nacional de lenguas originarias del Perú. Lima: Ministerio de Educación.

Montag, Susan

1979 Lecciones para el Aprendizaje del Idioma Cashinabua. Lima: Instituto Lingüístico de Verano.

Montaluisa Chasiquiza, Luis Octavio

2018 La estandarización ortográfica del quichua ecuatoriano: consideraciones históricas, dialectológicas y sociolingüísticas. Tesis doctoral. Lima: Pontificia Universidad Católica del Perú.

Montes Rodríguez, María Emilia

2004 Morfosintaxis de la lengua Tikuna (Amazonía colombiana). Colección Lenguas Aborígenes de Colombia, Descripciones. Bogotá: Universidad de los Andes / CESO / CCELA.

Noonan, Michael

2006 Grammar writing for a grammar-reading audience. En Perspectives on Grammar Writing. Eds., Thomas Payne y David Weber. Ámsterdam: John Benjamins, 113-126.

Olawsky, Knut

2006 A Grammar of Urarina. Berlín: Mouton de Gruyter.

Overall, Simon

2007 A Grammar of Aguaruna. Tesis doctoral. Melbourne: LaTrobe University.

2017 A Grammar of Aguaruna (Iiniá Chicham). Mouton Grammar Library. Berlín: De Gruyter Mouton. 
PARK, Marinell y Elisabeth WYSS

1995 Lecciones para el aprendizaje del quechua de San Martín. Vols. 1-3. Yarinacocha: Ministerio de Educación / Instituto Lingüístico de Verano.

PARKer, Gary

1963 La clasificación de los dialectos quechuas. Revista del Museo Nacional. XXXII, 241-252.

1965 Gramática del quechua ayacuchano. Lima: Plan de Fomento Lingüístico de la Universidad Nacional Mayor de San Marcos.

1976 Gramática quechua: Áncash-Huailas. Lima: Ministerio de Educación / Instituto de Estudios Peruanos.

PAYne, David L.

1978 The Phonology and Morphology of Axininca Campa (Apurucayali Campa). Tesis doctoral. Austin: University of Texas at Austin.

1981 The Phonology and Morphology of Axininca Campa (Apurucayali Campa). Arlington: The Summer Institute of Linguistics $\mathrm{y}$ the University of Texas at Arlington.

Payne, David L., Judith K. PAyne y Jorge SÁnchez S.

1982 Morfología, fonología y fonética del Ashéninca del Apurucayali (Campa Arawak preandino). Lima: Ministerio de Educación / Instituto Lingüístico de Verano.

Payne, Doris L. y Thomas E. Payne

1990 Yagua. En Handbook of Amazonian Languages. Vol. II. Eds., Desmond C. Derbyshire y Geoffrey K. Pullum. Berlín / Nueva York: Mouton de Gruyter, 249-474.

PAYNE, Doris Lander

1985 Aspects of the Grammar of Yagua: A Typological Perspective (Peru). Tesis doctoral. Los Ángeles: University of California at Los Angeles.

PaYne, Judith K.

1989 Lecciones para el aprendizaje del idioma ashéninca. Yarinacocha: Ministerio de Educación / Instituto Lingüístico de Verano. 
Pedrós, Toni

2018 Ashéninka y asháninka: ¿de cuántas lenguas hablamos? Cadernos de Etnolingüística. 6, 1-31.

PeÑA, Jaime

2015 A grammar of Wampis. Tesis doctoral. Eugene: University of Oregon.

Pike, Kenneth L.

1967 Language in relation to a unified theory of the structure of buman behavior. La Haya: Mouton.

Pontificia Universidad Católica del Perú

$\mathrm{s} / \mathrm{f} \quad$ Archivo Digital de Lenguas Peruanas (ADLP). Repositorio Institucional. Consultado: marzo-abril de 2019. <http:// repositorio.pucp.edu.pe/index/handle/123456789/124179>

PORTERIE-GutiérRez, Liliane

1992 Étude linguistique de l'Aymara septentrional (Pérou-Bolivie). París: AEA.

Quesada, Félix

1976 Gramática quechua: Cajamarca-Cañaris. Lima: Ministerio de Educación / Instituto de Estudios Peruanos.

Rice, Keren

2006 A typology of good grammars. En Perspectives on Grammar Writing. Eds., Thomas Payne y David Weber. Ámsterdam: John Benjamins, 143-172.

Russell, Robert L.

1975 Estudios panos 4: Una gramática transformacional del amabuaca. Serie Lingüística Peruana. Yarinacocha: Instituto Lingüístico de Verano.

SAMANEZ FlóReZ, David I.

1996 Gramática del quechua del Qosqo. Cuzco: Instituto Nacional de Cultura.

Santo Tomas, Domingo de

1560 Arte y vocabulario de la Lengua General del Perú, llamada Quichua. Valladolid: Francisco Fernandez de Cordoua, impressor de la M.R. 
[1560] 1995 Grammatica o Arte de la Lengua General de los Indios de los Reynos del Peru. Transliteración y estudio preliminar de Rodolfo Cerrón-Palomino. Cuzco: Centro de Estudios Regionales Andinos Bartolomé de Las Casas.

SEIFART, Frank

2005 The Structure and Use of Shape-Based Noun Classes in Miraña (North West Amazon). Tesis doctoral. Nimega: Radboud Universiteit.

Shimelman, Aviva

2014 A grammar of Southern Yauyos Quechua. Ms.

2017 A grammar of Yauyos Quechua. Berlín: Language Science Press.

SoARes, Marília Facó

1992 O suprassegmental em Tikuna e a teoria fonológica. Tesis doctoral. Campinas: Universidade Estadual de Campinas.

2000 O supra-segmental em Tikuna e a teoria fonológica: Investigação de aspectos de aspectos da suntaxe Tikuna: Volume I. Campinas: Editora da Unicamp.

Sola, Donald F. y Gary J. PARKer

1963 Spoken Ayacucho Quechua. Ithaca: Cornell University.

1964 The structure of Ayacucho Quechua. Ithaca: Cornell University.

Soto-Ruiz, Clodoaldo

1976 Gramática quechua: Ayacucho-Chanca. Lima: Ministerio de Educación / Instituto de Estudios Peruanos.

1979 Quechua: manual de enseñanza. Lima: Instituto de Estudios Peruanos.

SouzA, Emerson Carvalho de

2012 Aspectos de uma gramática Shawã (Pano). Tesis doctoral. Campinas: Universidade Estadual de Campinas.

Staly, Alicia, Patricia M. Davis y Harriet Kneeland

1979 Lecciones para el aprendizaje del idioma mayoruna. Yarinacocha: Instituto Lingüístico de Verano.

SwifT, Kenneth E.

1985 Morphology of Caquinte (Preandine Arawakan). Tesis de maestría. Arlington: University of Texas at Arlington. 
TARIFA AsCARrunz, Erasmo

1970 Suma Lajjra Aymara Parlaña/Gramática de la Lengua Aymara. La Paz: Editorial Don Bosco.

TAYLOR, Gerald

1996 El quechua de Ferreñafe: Fonología, morfología, léxico. Cajamarca: Acku Quinde.

1999 Método del Quechua Ferreñafano para hispanobablantes. Lima: Las Esmeraldas.

Thiesen, Wesley

1996 Gramática del idioma bora. Serie Lingüística Peruana. Yarinacocha: Ministerio de Educación / Instituto Lingüístico de Verano.

2008 Gramática del idioma bora. Serie Lingüística Peruana. Yarinacocha: Ministerio de Educación / Instituto Lingüístico de Verano.

Thiesen, Wesley y David Weber

2012 A Grammar of Bora with Special Attention to Tone. Vol. 148. SIL International Publications in Linguistics. Dallas: SIL International.

Thoron, Enrique de

1886 Grammaire et Dictionnaire Français-Kichua. París: Érnest Leroux.

Tiss, Frank

2004 Gramática da língua madiba (kulina). São Leopoldo: Oikos.

TORERo, Alfredo

1964 "Los dialectos quechuas". Anales Científicos de la Universidad Agraria. 2, 446-478.

Townsend, Elaine, Marlene Ballena y Kenneth E. SwifT

1988 Morfología del caquinte (arawak preandino). Vol. 25. Serie Lingüística Peruana. Lima: Ministerio de Educación / Instituto Lingüístico de Verano.

Tschudi, Johann Jakob von

1853 Die Kechua-Sprache. Viena: Wien Kaiserlich-Königliche Hofund Staatsdruckerei.

1884 Organismus der Khetšua-Sprache. Leipzig: F.A. Brockhaus. 
UNESCO

$\mathrm{s} / \mathrm{f} \quad$ Atlas de las lenguas en peligro del mundo. Consultado: $\mathrm{s} / \mathrm{f}$ $<$ http://www.unesco.org/languages-atlas/>.

Universidad de CALIFORNIA EN BERKELEy

$\mathrm{s} / \mathrm{f} \quad$ Survey of California and Other Indian Languages (SCOIL). Consultado: marzo-abril de 2019. <http://cla. berkeley.edu/>

Universidad de Hawái en Manoa

s/f Catalogue of Endangered Languages (ElCat). Consultado: s/f. <http://ling.hawaii.edu/research-current/projects/ elcat/>

UNIVERSIDAD DE LONDRES

s/f Endangered Languages Archive (ELAR). Repositorio Institucional de la Escuela de Estudios Orientales y Africanos (SOAS). Consultado: marzo-abril de 2019. <https://www. soas.ac.uk/elar/>

Universidad de TeXas en Austin

$\mathrm{s} / \mathrm{f} \quad$ Archive of the Indigenous Languages of Latin America (AILLA). Consultado: marzo-abril de 2019. <https://ailla. utexas.org/>

Valenzuela, Pilar M.

2003 Transitivity in Shipibo-Konibo Grammar. Tesis doctoral. Eugene: University of Oregon.

Vallejos Yopán, Rosa

2010 A grammar of Kokama-Kokamilla. Tesis doctoral. Eugene: University of Oregon.

2016 A grammar of Kukama-Kukamiria: A Language from the Amazon. Leiden: Brill.

Vuillermet, Marine

2012 Grammaire de l'ese ejja, langue tacana d'Amazonie bolivienne. Tesis doctoral. Lyon: Université Lumière Lyon 2.

Weber, David J.

1983

A Grammar Huallaga (Huánuco) Quechua. Tesis doctoral. Los Ángeles: University of California at Los Angeles. 
1989

A Grammar Huallaga (Huánuco) Quechua. Berkeley / Los Ángeles: University of California Press.

1996 Una gramática del quechua del Huallaga (Huánuco). Lima: Ministerio de Educación / Instituto Lingüístico de Verano.

Weber, Robert L., Heidi Coombs y David M. Coombs

1976 Gramática quechua: San Martín. Lima: Ministerio de Educación.

Wexler, Paul

1967 Beginning Aymara. A course for English speakers. Seattle: University of Washington.

Wojtylak, Katarzyna I.

2017 A Grammar of Murui (Bue): A Witotoan language of Northwest Amazonia. Tesis doctoral. Cairns: James Cook University.

Wroughton, James F.

1988 Major Clause Constituents of Conchucos (Áncash) Quechua. Tesis de maestría. Arlington: University of Texas at Arlington.

Wroughton, John R.

1996 Gramática y textos del quechua Shausba Huanca. Yarinacocha: Ministerio de Educación / Instituto Lingüístico de Verano.

ZARIQUIEY, Roberto

2011 A grammar of Kashibo-Kakataibo. Tesis doctoral. Melbourne: LaTrobe University.

2015 Bosquejo gramatical de la lengua Iskonawa. Boston: Latinoamericana Editores / CELACP.

2018 A grammar of Kakataibo. Berlín: Mouton de Gruyter.

ZARIQUiey, Roberto y Gavina Córdova

2008 Qayna, Kunan, Paqarin: Una introducción práctica al quechua chanca. Lima: Pontificia Universidad Católica del Perú.

Recepción: 21/05/2019

Aceptación: 10/10/2019 